\title{
Canonical NF-кB Promotes Lung Epithelial Cell Tumour Growth by Downregulating the Metastasis Suppressor CD82 and Enhancing Epithelial-to-Mesenchymal Cell Transition
}

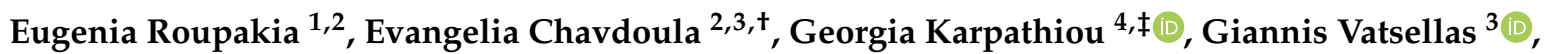 \\ Dimitrios Chatzopoulos ${ }^{3}$, Angeliki Mela ${ }^{5}$, Jennifer M. Gillette ${ }^{6}$, Katharina Kriegsmann ${ }^{7}$, Mark Kriegsmann ${ }^{8}(\mathbb{D}$,
} Anna Batistatou ${ }^{4}$, Anna Goussia ${ }^{4}$, Kenneth B. Marcu ${ }^{3,9}$, , Emmanouil Karteris ${ }^{10}$, Apostolos Klinakis ${ }^{3}$ and Evangelos Kolettas $1,2, * \mathbb{B}$

check for updates

Citation: Roupakia, E.; Chavdoula,

E.; Karpathiou, G.; Vatsellas, G.; Chatzopoulos, D.; Mela, A.; Gillette, J.M.; Kriegsmann, K.; Kriegsmann, M.; Batistatou, A.; et al. Canonical NF- $\kappa B$ Promotes Lung Epithelial Cell Tumour Growth by Downregulating the Metastasis Suppressor CD82 and Enhancing Epithelial-to-Mesenchymal Cell Transition. Cancers 2021, 13, 4302. https://doi.org/10.3390/

cancers 13174302

Academic Editor: David Wong

Received: 8 July 2021

Accepted: 24 August 2021

Published: 26 August 2021

Publisher's Note: MDPI stays neutral with regard to jurisdictional claims in published maps and institutional affiliations.

Copyright: (C) 2021 by the authors Licensee MDPI, Basel, Switzerland. This article is an open access article distributed under the terms and conditions of the Creative Commons Attribution (CC BY) license (https:// creativecommons.org/licenses/by/ $4.0 /)$
1 Laboratory of Biology, School of Medicine, Faculty of Health Sciences, Institute of Biosciences, University Research Centre, University of Ioannina, University Campus, 45110 Ioannina, Greece; ev.roupakia@gmail.com

2 Biomedical Research Division, Institute of Molecular Biology and Biotechnology, Foundation for Research and Technology, University of Ioannina Campus, 45115 Ioannina, Greece; echavdoula@gmail.com

3 Biomedical Research Foundation, Academy of Athens (BRFAA), 4 Soranou Ephessiou Street, 11527 Athens, Greece; gvatsellas@bioacademy.gr (G.V.); dimitrischat@gmail.com (D.C.); kenneth.marcu@stonybrook.edu (K.B.M.); aklinakis@bioacademy.gr (A.K.)

4 Laboratory of Pathology, School of Medicine, Faculty of Health Sciences, University of Ioannina, 45500 Ioannina, Greece; gakarpath@yahoo.gr (G.K.); abatista@uoi.gr (A.B.); agoussia@uoi.gr (A.G.)

5 Department of Pathology and Cell Biology Columbia University Medical Center, Irving Comprehensive Cancer Research Center, Columbia University, New York, NY 10032, USA; am2904@cumc.columbia.edu

6 Department of Pathology, School of Medicine, University of New Mexico, Albuquerque, NM 87131, USA; jgillette@salud.unm.edu

7 Department of Internal Medicine V, University Hospital Heidelberg, 69120 Heidelberg, Germany; Katharina.Kriegsmann@med.uni-heidelberg.de

8 Institute of Pathology, University Hospital Heidelberg, 69120 Heidelberg, Germany; Mark.Kriegsmann@med.uni-heidelberg.de

9 Department of Biochemistry and Cell Biology, Microbiology and Pathology, Stony Brook University, New York, NY 11794, USA

10 Division of Biosciences, Department of Life Sciences, College of Health, Medicine and Life Sciences, Brunel University London, Uxbridge, Middlesex, London UB8 PH, UK; emmanouil.karteris@brunel.ac.uk

* Correspondence: ekoletas@uoi.gr; Tel.: +30-26510-07578; Fax: +30-26510-07863

+ Present address: Department of Cancer Biology and Genetics, College of Medicine, Arthur G. James Comprehensive Cancer Center, The Ohio State University, Columbus, OH 43210, USA.

$\ddagger$ Present address: Department of Pathology, University Hospital of Saint-Etienne, Avenue Albert Raimond, 42270 Saint-Priest-en-Jarez, France.

Simple Summary: Canonical NF- $\mathrm{kB}$ signalling pathway acts as a tumour promoter in several types of cancer including non-small cell lung cancer (NSCLC), but the mechanism(s) by which it contributes to NSCLC is still under investigation. We show here that NF- $\mathrm{kB}$ RelA/p65 is required for the tumour growth of human NSCLC cells grown in vivo as xenografts in immune-compromised mice. RNAseq transcriptome profile analysis identified the metastasis suppressor CD82/KAI1/TSPAN27 as a canonical NF- $\mathrm{kB}$ target. Loss of CD82 correlated with malignancy. RelA/p65 stimulates cell migration and epithelial-to-mesenchymal cell transition (EMT), mediated, in part, by CD82/KAI1, through integrin-mediated signalling, thus, identifying a mechanism mediating NF- $\mathrm{kB}$ RelA/p65 lung tumour promoting function.

Abstract: Background: The development of non-small cell lung cancer (NSCLC) involves the progressive accumulation of genetic and epigenetic changes. These include somatic oncogenic KRAS and EGFR mutations and inactivating TP53 tumour suppressor mutations, leading to activation of canonical NF- $\kappa B$. However, the mechanism(s) by which canonical NF- $\kappa B$ contributes to NSCLC is still under investigation. Methods: Human NSCLC cells were used to knock-down RelA/p65 (RelA/p65 ${ }^{\mathrm{KD}}$ ) and investigate its impact on cell growth, and its mechanism of action by employing RNA-seq analysis, qPCR, immunoblotting, immunohistochemistry, immunofluorescence and functional assays. 
Results: RelA/p65 ${ }^{\mathrm{KD}}$ reduced the proliferation and tumour growth of human NSCLC cells grown in vivo as xenografts in immune-compromised mice. RNA-seq analysis identified canonical NF- $\mathrm{B}$ targets mediating its tumour promoting function. RelA $/ \mathrm{p} 65^{\mathrm{KD}}$ resulted in the upregulation of the metastasis suppressor CD82/KAI1/TSPAN27 and downregulation of the proto-oncogene ROS1, and LGR6 involved in Wnt/ $\beta$-catenin signalling. Immunohistochemical and bioinformatics analysis of human NSCLC samples showed that CD82 loss correlated with malignancy. RelA/p65 ${ }^{\mathrm{KD}}$ suppressed cell migration and epithelial-to-mesenchymal cell transition (EMT), mediated, in part, by CD82/KAI1, through integrin-mediated signalling involving the mitogenic ERK, Akt1 and Rac1 proteins. Conclusions: Canonical NF- $\mathrm{kB}$ signalling promotes NSCLC, in part, by downregulating the metastasis suppressor CD82/KAI1 which inhibits cell migration, EMT and tumour growth.

Keywords: human NSCLC models; NF-кB RelA/p65; RNA-seq; CD82; cell migration; EMT; integrin signalling

\section{Introduction}

Non-small cell lung cancer (NSCLC), one of the most common cancers worldwide, with high incidence and mortality rates, is histologically divided into three major subtypes: adenocarcinoma (LUAD) ( 70\%), squamous cell carcinoma (LUSC) $(\sim 20 \%)$, and large cell lung carcinoma ( 10\%). The development of these histological subtypes occurs through the progressive accumulation of genetic and epigenetic events, with inactivating mutations in the p53 tumour suppressor detected in $>50 \%$ of the cases, being common to all subtypes [1-9]. The most commonly mutated genes in LUAD include KRAS and EGFR, and at a lower frequency BRAF, ALK, PIK3CA and ROS1 oncogenes, and in the tumour suppressor genes LKB1 (STK11), NF1 and PTEN [3,4,6,8,9]. Murine cancer models have been used to evaluate the impact of the genetic changes in LUAD onset, development and progression [10]. Importantly, several studies have revealed a link between oncogenic K-Ras [11-14] or EGFR proteins [15-17] and increased canonical NF- $\kappa$ B activity in NSCLC [7].

NF- $\mathrm{B}$ transcription factors (TFs) are critical regulators of pro-inflammatory and stresslike responses. NF- $\mathrm{kB}$ TFs bind to DNA as heterodimers or homodimers composed of 5 subunits: RelA/p65, c-Rel, RelB, p50, p52. All NF-kB family members contain an Nterminal DNA binding and dimerisation domain known as the Rel homology domain. The c-Rel (C-REL), p65/RelA (RELA) and RelB (RELB) subunits contain a C-terminal transactivation domain, but $\mathrm{p} 50$ and $\mathrm{p} 52$, which are derived by processing of the larger precursors p50/p105 (NF-kB1) and p52/p100 (NF-kB2), respectively, lack a transcriptional activation domain. Activation of NF- $\mathrm{BB}$ is achieved by two main signalling pathways: An IKK $\beta$ mediated canonical NF- $\kappa B$ pathway and an IKK $\alpha$-mediated non-canonical or alternative NF- $\kappa$ B pathway. In the former, c-Rel/p50 and RelA(p65)/p50 heterodimers are restrained in the cytoplasm of most cells not experiencing a pro-inflammatory/stress-like response by NF- $\kappa$ B inhibitors, the I $\kappa$ Bs bound to them. Activation of canonical NF- $\kappa$ B pathway is initiated by the phosphorylation of serines (Ser) 32 and 36 of I $\mathrm{B} \alpha$ causing its ubiquitination and proteasomal degradation, resulting in c-Rel/p50 or p65/50 heterodimer nuclear translocation to regulate target gene expression. Phosphorylation of $\mathrm{I} \kappa \mathrm{B} \alpha$ at Ser32/36 is mediated by the IKK signalsome complex composed of the upstream activating IKK $\alpha$ and IKK $\beta$ Ser/Thr kinases, and NEMO/IKK $\gamma$, a regulatory/adaptor protein. Activation of IKK $\beta$ by Ser177/181 phosphorylation is NEMO-dependent and occurs in response to pro-inflammatory and stress signals. Activation of the non-canonical or alternative NF- $\kappa B$ pathway involves the NF- $\kappa$ B Inducing Kinase (NIK)-dependent phosphorylation of IKK $\alpha$ at Ser176/180. Activated IKK $\alpha$ then mediates the phosphorylation of $\mathrm{p} 100 / \mathrm{NF}-\mathrm{KB} 2$, inducing its ubiquitination and proteasome-dependent processing yielding the mature p52 subunit and p52/RelB heterodimers that translocate to the nucleus and regulate non-canonical NF-KB target genes [18-21]. 
The NF- $\mathrm{B}$ TFs can either activate or repress target gene transcription in different physiological contexts [19,22,23]. NF-kB-induced genes regulate cancer cell proliferation, survival, metastasis and angiogenesis [18-20]. NF- $\mathrm{KB}$ TFs function as tumour promoters within transformed cells, but also influence the host's innate immune response to cancer cells by regulating functions of infiltrating lymphocytes and macrophages and promoting inflammation in the tumour microenvironment [21].

The NF- $\mathrm{B}$ TFs and their immediate upstream signalling components are aberrantly expressed and/or activated in inflammatory lung diseases and NSCLC and have been implicated in the unfavourable prognosis of patient survival $[7,24]$. Several studies including murine models have revealed a link between oncogenic KRAS [11-14] and EGFR [15-17] and increased canonical NF-KB activity in mouse lung cancer models and human lung epithelial cells, and the induction of an inflammatory response in lung tumours. Similarly, murine models have uncovered functional effects of IKK $\beta$ and of the canonical NF- $\mathrm{B}$ RelA/p65 subunit in urethane- induced inflammation and NSCLC $[25,26]$. In both the urethane- and the oncogene-induced mouse lung cancer models suppression of canonical

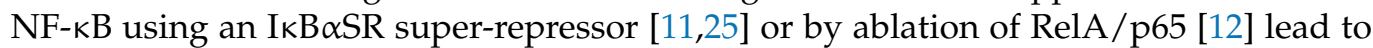
impairment of tumour growth and spread in conjunction with the accumulation of apoptotic cells [12]. Similarly, ablation of IKK $\beta$ in lung epithelium [13] or in myeloid cells [14] reduced K-Ras ${ }^{\mathrm{G} 12 \mathrm{D}}$-induced inflammation, proliferation and tumour growth in mice. Ablation of IKK $\beta$ in alveolar type (AT)-II lung cells also reduced urethane-induced LUAD [26]. Mouse strains susceptible to urethane-induced lung carcinogenesis exhibit NF- $\kappa \mathrm{B}$ activation and lung inflammation, in the airway and AT-II lung cells and macrophages suggesting that canonical NF- $\mathrm{kB}$ signalling in airway epithelium is required for urethane-induced lung carcinogenesis [25].

However, despite the aforementioned studies on the requirement and the tumour promoting role of canonical NF- $\kappa$ B in human and mouse NSCLC, the underlying mechanisms are still under investigation. By performing an integrative cytogenetic and gene expression analysis of NSCLC and SCLC cell lines and tumours, a recurring amplification at chromosome 11p13 was identified, that only contained TNF receptor-associated factor 6 (TRAF6). Inhibition of TRAF6 in human lung cancer cells suppressed NF- $\mathrm{kB}$ activation, anchorage-independent and tumour growth. Thus, TRAF6 acted as an oncogene leading to the constitutive NF- $\kappa B$ activation in K-Ras-driven lung cancers [27]. Ablation of IKK $\beta$ in K-Ras ${ }^{G 12 D}$-induced LUAD in mice resulted in decreased tumour growth and burden due to reduced AT-II lung cell proliferation. This was due to the down-regulation of several E2F target genes implicated in cell cycle progression, the mitotic checkpoint Ser/Thr kinase BUB1, and to Timp1 (tissue inhibitor of metalloproteinase 1) which was identified as a canonical NF- $\kappa B$ target gene involved in lung tumourigenesis [13]. Activation of canonical NF- $\mathrm{BB}$ in response to EGFR oncogene inhibition in mutant EGFR-bearing human and mouse lung cancer cells, drives tumour cell survival and residual disease in lung cancer via several established regulators of canonical NF- $\kappa$ B signalling and cell survival such as TNFAIP3 (TNF $\alpha$-induced protein 3), BIRC3 (c-IAP2, TNFR2-TRAF signalling complex protein) and IL-6 [16].

In the present study, we show that RelA/p65 functions as an epithelial tumour promoter in human NSCLC cell lines (harbouring either wild-type or mutant KRAS and TP53 genes) grown as tumour xenografts in immune-compromised NSG mice. We identified the metastasis suppressor CD82 as a RelA/p65 target. CD82 expression was downregulated in LUAD and LUSC. We also provide evidence that RelA/p65's tumour promoting action in NSCLC is due to, at least in part, the downregulation of CD82 that inhibits cell migration and EMT, and the stimulation of ERK and Rac1 through the engagement of integrin-mediated signalling as revealed by bioinformatics analysis. 


\section{Results}

2.1. RelA/p65 Was Required for Tumour Growth In Vivo

A549 and H1437 lung cancer cells were stably transfected with the vectors pS-Puro and pS-Puro-shp65 [28,29] followed by puromycin selection. Immunoblot analysis verified the efficient knock-down of RelA/p65 expression in the stably shp65-transfected human NSCLC cell lines compared to their vector control counterparts (Figure 1A).

A

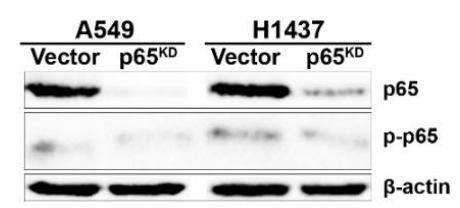

B
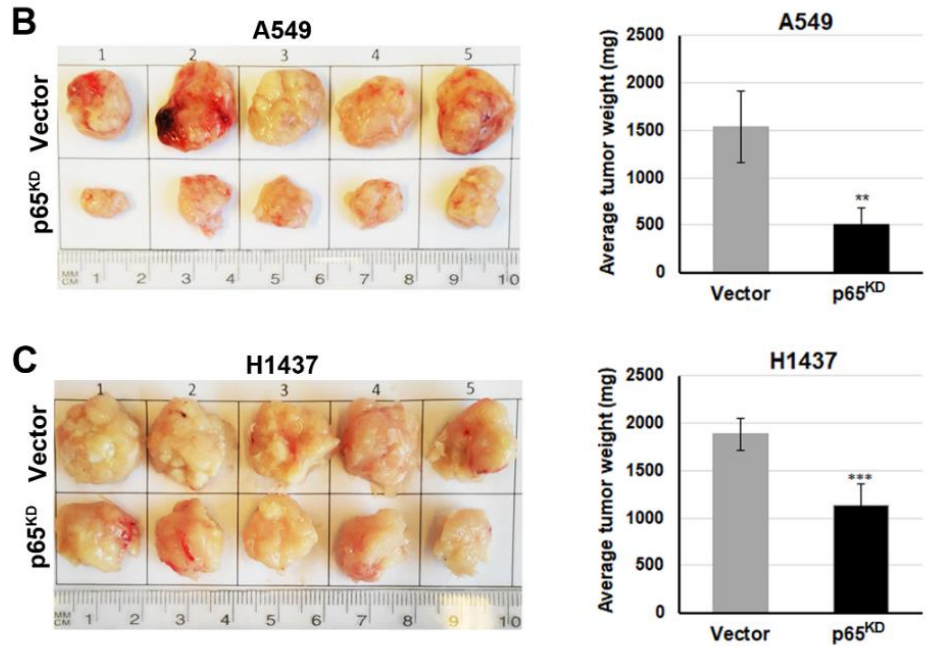

D
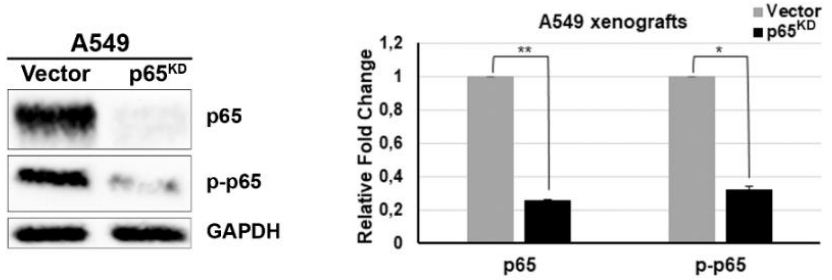

E
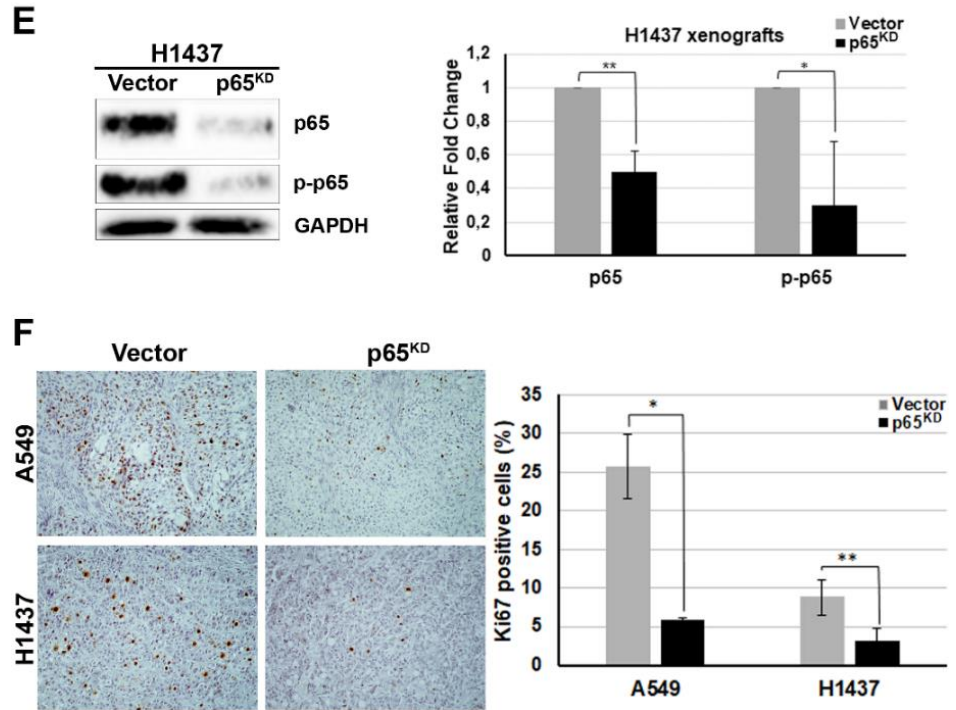

Figure 1. Canonical NF- $\mathrm{kB}$ signalling is required for the growth of human NSCLC in murine xenografts. (A) Generation of RelA/p65-compromised A549 and H1437 human lung cancer cells. 
Cells were transfected with either the control vector pSuper-Puro or a pSuper-Puro-sh65 carrying a shRNA against RelA/p65 (p65 ${ }^{\mathrm{KD}}$ ) and selected in puromycin to generate stable cell lines. Total proteins extracted were analysed by immunoblotting for the expression of RelA/p65, or $\beta$-actin as a reference control. (B,C) A549 and $\mathrm{H} 1437$ cells and their RelA/p65 ${ }^{\mathrm{KD}}$ derivatives grown in vivo as tumour xenografts. $2 \times 10^{6}$ cells in $200 \mu \mathrm{L}$ per injection of each of our control and RelA/p65 ${ }^{\mathrm{KD}}$ A549 and H1237 cells were inoculated subcutaneously into the flanks of NSG mice and maintained for 4 weeks and grown in vivo as tumour xenografts. Comparative photographs of tumour xenografts are shown in the left panels and quantitative analysis of the tumours are shown in the right panels. Significant differences were observed in tumour sizes comparing vector controls to their RelA/p $65^{\mathrm{KD}}$ derivatives for each of the two human NSCLC cell lines 4 weeks after their inoculation into immunecompromised mice. H1437 $(n=9 \text { mice })^{* * *} p<0.005$; A549 $(n=9 \text { mice })^{*} p<0.05$ by two-tailed Student's $t$-tests. (D,E) Representative immunoblots showing the expression of RelA/p65 in vector control and RelA/p65 KD human lung cancer cells A549 (D) and H1437 (E) grown as tumour xenografts in vivo. Tumours were excised from the animals, and total proteins were isolated and analysed by immunoblotting for the expression of RelA/p65, phospho-p65 (S536) or GAPDH as a reference control (left panels). Quantification of protein expression levels is also provided (right panels) $\left({ }^{*} p<0.05,{ }^{* *} p<0.01\right.$, by two-tailed Student's $t$-test). (F) Paraffin-embedded tissue sections from the excised tumours were analysed by immunohistochemistry for the expression of the proliferation antigen Ki67 (magnification 200X) $\left({ }^{*} p<0.05,{ }^{* *} p<0.01\right.$, by two-tailed Student's $t$-test).

Next, we investigated if NF- $\mathrm{BB}$ is activated in cultured cells by immunoblotting and luciferase assays by transfecting the A549 and H1437 cells with pGL3, pCMV-Luc and pGL3-5x $\kappa B$-luc reporter plasmids. RelA/p65 was phosphorylated in cultured cells but the expression of the phospho-p65 form was low (Figure 1). Luciferase activity was increased in the cells transiently transfected with the pGL3-5x $\kappa B$-luc reporter compared to pGL3 basic reporter plasmid but it was at much lower levels compared to CMV-driven luciferase expression (Figure S1). Collectively, these data showed that canonical NF- $\mathrm{B}$ was constitutively activated in cultured cells but at low levels.

Next, we analysed the impact of $\mathrm{p} 65^{\mathrm{KD}}$ on cancer cell growth in vitro by constructing growth curves using the IncuCyte live-imaging system. Downregulation of p65 did not impair the proliferation of A549 or H1437 cells grown as monolayers in vitro. Analysis of cell apoptosis showed that $\mathrm{p} 65^{\mathrm{KD}}$ did not affect early or late apoptosis and necrosis (Figure S2).

Next, we investigated the role of RelA/65 in human lung tumour cell growth in vivo and its mechanism of action. To this end, we injected control and RelA/p65 ${ }^{\mathrm{KD}}$ A549 and H1437 cells into either side of immune-compromised NSG (NOD-SCID-IL2Rgamma) mice and allowed them to grow in vivo as xenografts. RelA/p65 ${ }^{\mathrm{KD}}$ human NSCLC cell lines presented significantly smaller tumours compared to their wild-type vector control cells. Representative images of dissected tumours grown as xenografts of control A549 and $\mathrm{H} 1437$ cells and their RelA/p65 ${ }^{\mathrm{KD}}$ derivatives are shown, and statistical analyses of tumour weight differences between control and RelA/p $65^{\mathrm{KD}}$ tumour xenografts are provided, respectively (Figure $1 \mathrm{~B}, \mathrm{C}$ ). This is in agreement with our recent studies showing that IKK $\beta$ is required for urethane-induced NSCLC in transgenic mice [26].

To confirm the efficient downregulation of RelA/p65 in vivo, total protein lysates were isolated from the excised tumours and analysed for the expression of p65 and phospho-p65 (S536) by immunoblotting together with statistical analysis (Figure 1D,E). Representative immunoblots are presented showing the expression of RelA/p65 and phospho-p65 (S536) in vector control and RelA/p65 ${ }^{\mathrm{KD}}$ human lung cancer cells A549 and H1437 grown as tumour xenografts in vivo.

Importantly, NF- $\mathrm{kB}$ RelA/p65 was also activated in cells grown as tumour xenografts in vivo, as documented by the expression of the phosphorylated form of RelA/p65, further suggesting that it is required for tumour growth in vivo (Figure 1D). 
Immunohistochemical staining of tumour paraffin-embedded sections for the expression of Ki67 proliferation antigen showed that the RelA/p65 KD human NSCLC cell lines displayed reduced Ki67 expression compared to vector control counterparts (Figure 1F), indicating that reduced cell proliferation accounts for the decreased tumour growth in vivo in mice.

Taken together, these findings suggest that canonical NF- $\kappa \mathrm{B}$ signalling was required for the tumour growth human lung cancer cells in in vivo murine xenografts, hence acting as a tumour promoter of human NSCLC growth.

\subsection{Up-Regulation of the Metastasis Suppressor CD82/KAI1 and Down-Regulation of the Proto-Oncogene ROS1 in RelA/p65 ${ }^{K D}$ Human Tumours Grown in Immune-Compromised Mice}

To elucidate the possible molecular mechanisms of action of RelA/p65 in human lung epithelial cancer cells as a NSCLC tumour promoter, we performed a series of unbiased whole gene expression profiling by transcriptome sequencing followed by bioinformatics analysis. Multiple RNA-seq experiments were carried out to compare the transcriptomes of vector control and RelA/p65 ${ }^{\mathrm{KD}}$ human A549 and H1437 lung cancer cells grown as tumour xenografts to identify differentially expressed transcripts associated with RelA/p65 ${ }^{\mathrm{KD}}$.

Venn diagrams and heat maps of Differentially Expressed Genes (DEGs) in the vector control versus RelA/65 $\mathrm{KD}$ tumour xenografts of human A549 and H1437 NSCLC cells revealed changes in a small number of genes (Figure 2A,B). More specifically, as shown in the Venn diagrams and the heat maps, upon RelA/p65 knock-down, 13 genes in common were upregulated and 10 genes in common were downregulated (CHL1, LGR6, FAM20A, PLAU, DEFB1, CYP2C9, ANXA10, ROS1, C1R, and C1S) in the A549 and H1437 tumours.

Some of the upregulated genes encode metabolic enzymes such as HMGSB2 encoding the mitochondrial enzyme 3-hydroxy-3-methylglutaryl-CoA synthase 2, which catalyses the first reaction of ketogenesis, and CERS4 encoding the enzyme ceramide synthase 4 that catalyses the formation of ceramide from sphinganine and acyl-CoA. Upregulated genes encoding membrane proteins were also identified including TMPRSS2, SLC16A9 ( $\left.\mathrm{B}^{0} \mathrm{AT} 1\right), T M E M 125, C A C N A 1 H, S C N N 1 A$ and $C R A C R 2 A$, and the first two genes have been involved in SARS-CoV-2 virus entry via ACE2, into airway epithelial cells causing Covid-19 [30-32] which is linked to inflammatory responses [33-36].

Some of the downregulated genes include CHL1 which encodes the cell adhesion molecule L1CAM2, CYP2C9 encoding a member of the cytochrome P450 family involved in drug metabolism, and $C 1 R$ and $C 1 S$ encoding components of the complement system C1 complex.

LGR6 encoding a Leucine Rich Repeat Containing G Protein-Coupled Receptor (GPCR)6, is an epithelial lung stem cell marker involved in the activation of Wnt/ $\beta$-catenin signalling implicated in the generation and maintenance of cancer stem cells and metastasis [37,38].

Amongst the common upregulated genes was the metastasis suppressor gene CD82/KAI1 encoding a tetraspanin (TSPAN27) [39-41], and amongst the common downregulated genes was the proto-oncogene ROS1 encoding an orphan type I transmembrane Receptor Tyrosine Kinase (RTK) [42], both of which have been implicated in lung cancer (Figure 2).

\subsection{Downregulation of p65 Affected the Expression of CD82 and ROS1 in Human Lung Cancer Cells}

To experimentally validate the changes in expression of CD82 and ROS1, total RNA isolated from vector control and p65 ${ }^{\mathrm{KD}}$ A549 and H1437 cancer cells grown in culture were analysed by real-time qPCR (Figure 3). Loss of RelA/p65 in human NSCLC cells resulted in the upregulation of CD82/KAI1 (Figure 3A) and the downregulation of ROS1 protooncogene (Figure 3B) mRNA levels. The protein expression levels of CD82 in cultured cells was also investigated by immunoblotting and compared to HFL- 1 and MRC-5 HDFs. $\mathrm{RelA} / \mathrm{p} 65^{\mathrm{KD}}$ resulted in the upregulation of CD82 protein expression to levels similar to those detected in normal HDFs (Figure 3C). 


\section{A Up-regulated Genes}
A549
95

\section{Down-regulated Genes}

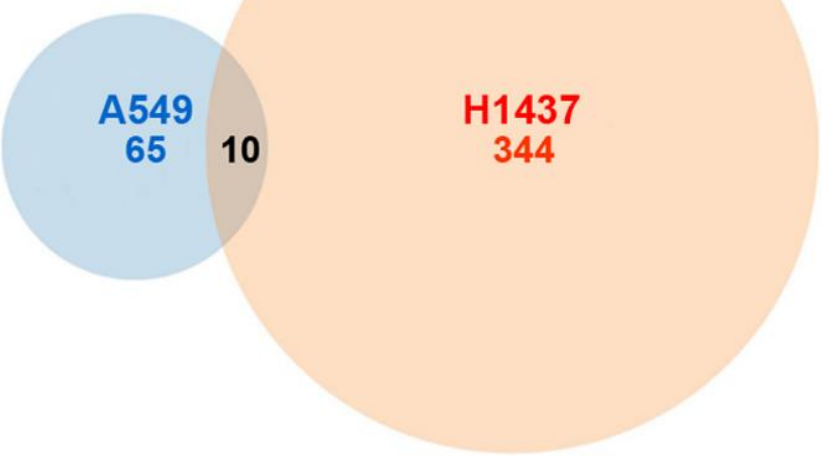

Common down

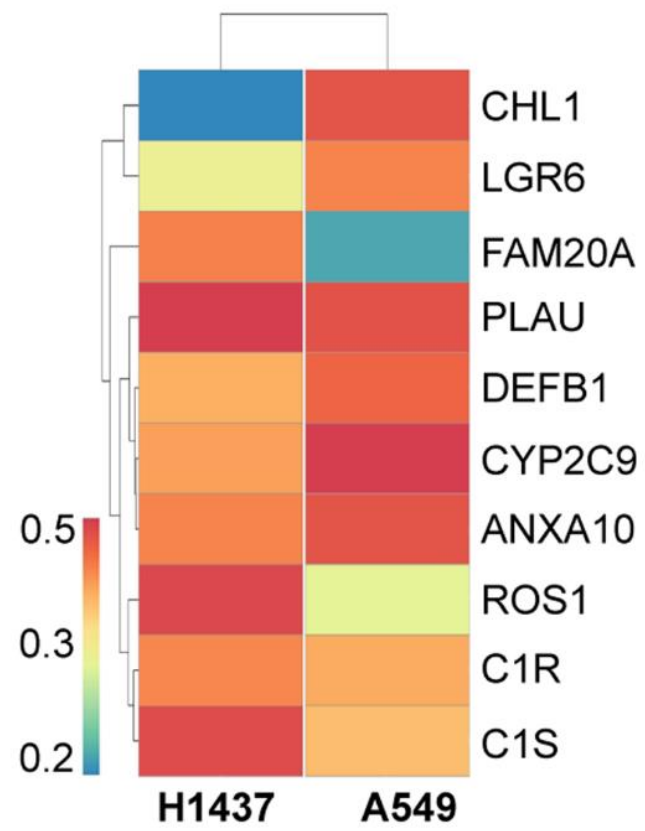

Figure 2. Gene expression profile by multiple RNA-seq experiments (three biological replicates per each cell line) followed by bioinformatics analysis of RelA/p65-compromised human tumours grown as xenografts in immune-compromised mice. (A) Following RNA-seq and bioinformatics comparative analysis, Venn diagrams were generated showing 13 genes in common up-regulated, and 10 genes in common down-regulated in both human A549 and H1437 NSCLC tumours; (B) heat maps of the common upregulated (left) and downregulated (right) genes in both cell lines that were increased or decreased by at least 2-fold in the tumour xenografts of the RelA/p65 ${ }^{\mathrm{KD}}$ human A549 and H1437 NSCLC tumours compared to their vector control counterparts. 

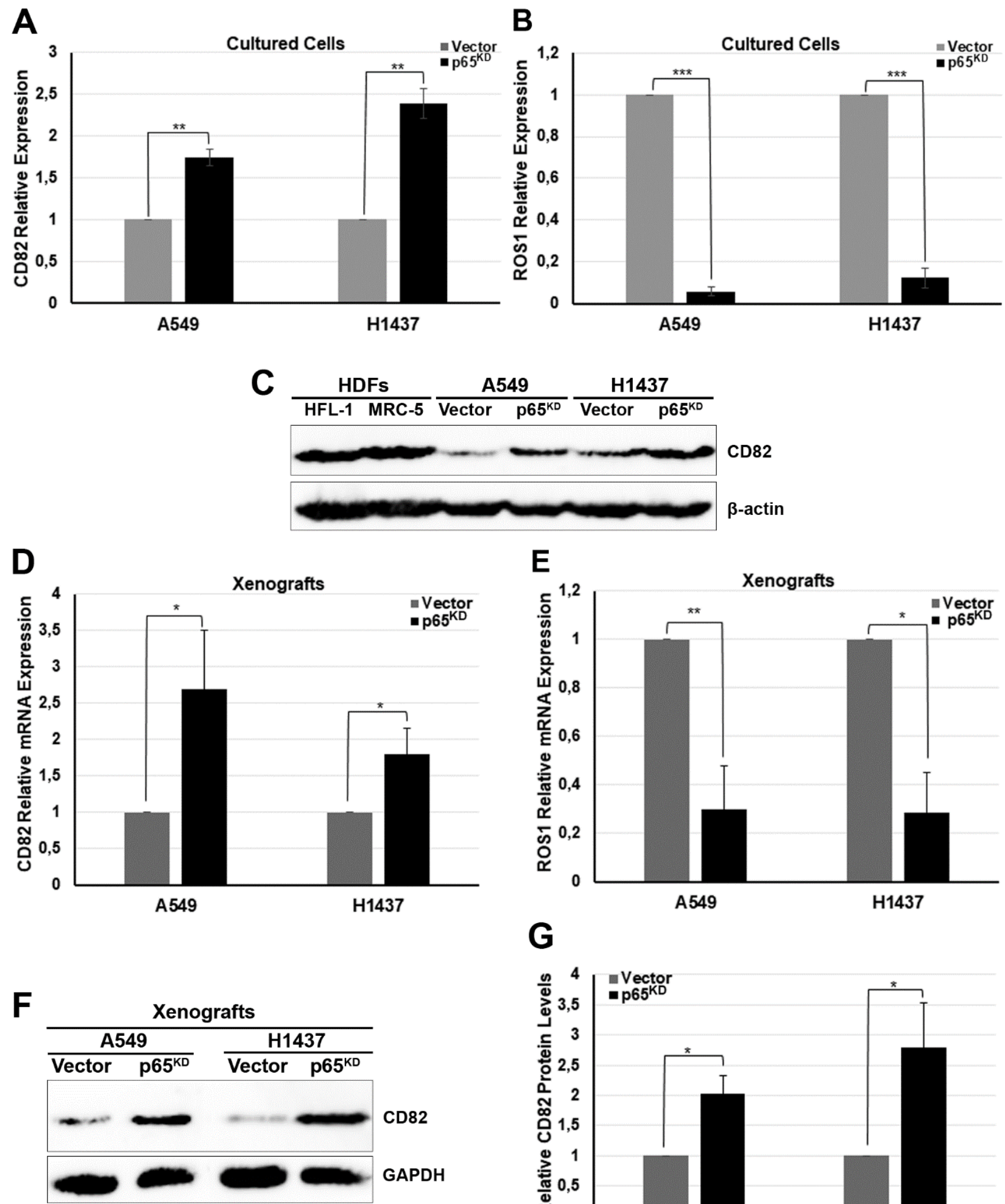

\section{G}

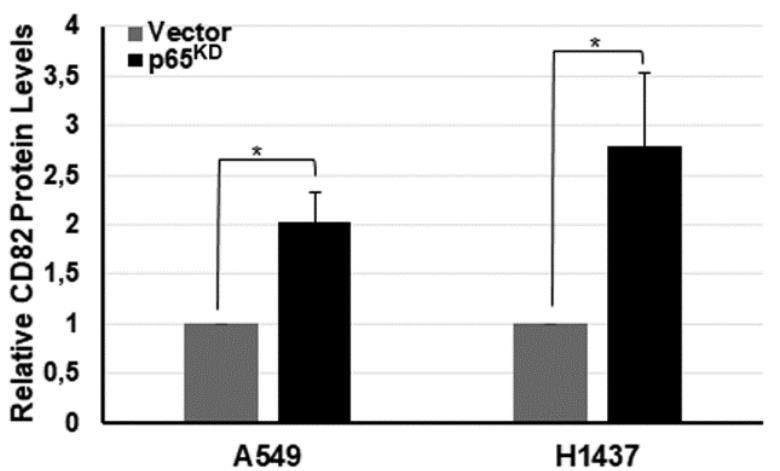

Figure 3. NF- $\mathrm{kB}$ p65 regulates the expression of ROS1 and CD82 in vitro and in vivo. (A,B) Total RNA was isolated from vector control and $\mathrm{p} 65^{\mathrm{KD}} \mathrm{A} 549$ and $\mathrm{H} 1437$ human lung cancer cells grown in vitro and analysed for the expression of CD82 (A) or ROS1 (B) mRNA by qPCR $(n=3)$. (C) Total protein lysates were isolated from normal lung HDFs, HFL-1 and MRC-5, and from vector control and p65 ${ }^{\mathrm{KD}} \mathrm{A} 549$ and $\mathrm{H} 1437$ cancer cells grown in vitro and analysed for the expression of CD82 or $\beta$-actin as a reference control by immunoblotting. (D,E) Total RNA isolated from vector control and p65 ${ }^{\mathrm{KD}}$ A549 and H1437 cells grown as tumour xenografts in mice was analysed for the expression of (D) CD82 and (E) ROS1 mRNA by qPCR $(n=3)$. RNA polymerase II was used as the reference control gene. (F) Total protein lysates were isolated from vector control 
and p65 ${ }^{\mathrm{KD}} \mathrm{A} 549$ and $\mathrm{H} 1437$ human lung cancer cells grown as tumours in in vivo xenografts in mice and analysed for the expression of CD82 or GAPDH as a reference control by immunoblotting. (G) Quantitative analysis of CD82 expression in vector control and p65 ${ }^{\mathrm{KD}}$ A549 and H1437 cancer cells grown in vivo $(n=3)$. All statistical analysis is a result of three biological replicates using a two-tailed Student's $t$-test $\left({ }^{*} p<0.05,{ }^{* *} p<0.01,{ }^{* * *} p<0.001\right.$, bars represent mean $\left.\pm \mathrm{SD}\right)$. The panels in Figure 3F resulted from the joining of strips of different blots. For all quantification analysis raw, unprocessed images were used.

Next, we investigated the expression of CD82 (Figure 3D) and ROS1 (Figure 3E) mRNA by real-time qPCR in vector control and RelA/p65 ${ }^{\mathrm{KD}}$ A549 and H1437 cancer cells grown as tumour xenografts in mice. Loss of RelA/p65 in human NSCLC cells grown as tumours in vivo lead to the upregulation of CD82/KAI1 and to the downregulation of ROS1 proto-oncogene mRNA levels. The protein expression levels of CD82 in the tumours were also investigated by immunoblotting. Loss of p65 resulted in the upregulation of CD82 protein levels in both human NSCLC lines (Figure 3F,G). Collectively, these data confirmed that both CD82/KAI1 and ROS1 are RelA/p65 targets.

\subsection{Decreased Expression of CD82/KAI1 in Human Lung Cancer Tissues}

Initially, we analysed the expression of CD82/KAI1 in whole sections of 16 patients with LUAD and 13 patients with LUSC. It was found that expression of CD82/KAI1 was decreased with the progression of human lung cancer (Figure S3A).

CD82 expression was analysed by immunohistochemistry in tissue microarrays (TMAs) that consisted of normal lung tissue (NLT), and samples of patients with LUAD and LUSC (Figure 4A). CD82 expression was significantly decreased in tumour versus normal lung tissue $(p<0.001)$, while there was also a significant difference between tumour types as only $6 \%$ of the LUAD samples were found positive for CD82 expression compared to $22 \%$ of LUSC patient samples $(p<0.05)$ (Figure 4 B).

In addition to our results, bioinformatics analysis showed that CD82 is significantly downregulated in LUAD $(p<0.05)$ and in LUSC (albeit non-significantly) compared to the normal lung tissue (GTEX) (Figure S3B), in both males and females suggesting no correlation between CD82 expression and the sex of the patients (Figure S3C). There was no correlation between CD82 expression and the stage of the NSCLC patients (Figure S3D), and also based on the staining of whole sections of early and advanced stage NSCLC (data not shown), suggesting that once malignancy is established, CD82 expression is downregulated with a small and insignificant reduction with disease progression.

Recent studies showed that $\mathrm{CD}^{+}$tissue infiltrating lymphocytes (TILs) is the best candidate marker for immune cells in NSCLC, with a prognostic efficacy in both LUAD and LUSC [43]. Hence, we investigated the presence of CD8 $8^{+}$TILs in a set of 29 NSCLC patient's whole sections. $\mathrm{CD} 8^{+}$TILs were increased in the intra- and peri-tumoural compartment of CD82 negative tumours. However, this difference did not reach statistical significance (Figure S4 and Table S1).

To gain a better insight of immune cells in NSCLC, we expanded our observations on single cell analysis of human immune cells in lung cancer using the Single Cell Portal [44]. Using T-distributed Stochastic Neighbour Embedding (tSNE) - a machine learning algorithm for visualisation - distinct cell sub-populations appear to express CD82 (Figure S5A). Specifically, sporadic expression was noted in neutrophils, T-cells, B-cells and mast cells (Figure S5B).

\subsection{Downregulation of p65 Reduced Cell Migration and Enhanced the Epithelial Cell Phenotype}

Because loss of RelA/p65 resulted in a significant decrease in tumour growth and the induction of the metastasis suppressor CD82, we next investigated the impact of p65 on cell migration in vitro using the wound healing assay. In confluent monolayers of control and p65 ${ }^{\mathrm{KD}}$ A549 and H1437 cancer cells a scratch was generated and the cells were allowed to heal the wound by establishing new cell-cell contacts. Loss of p65 in both A549 (Figure 5A) and H1437 (Figure 5B) cancer cells profoundly reduced cell migration compared to vector control cells. 

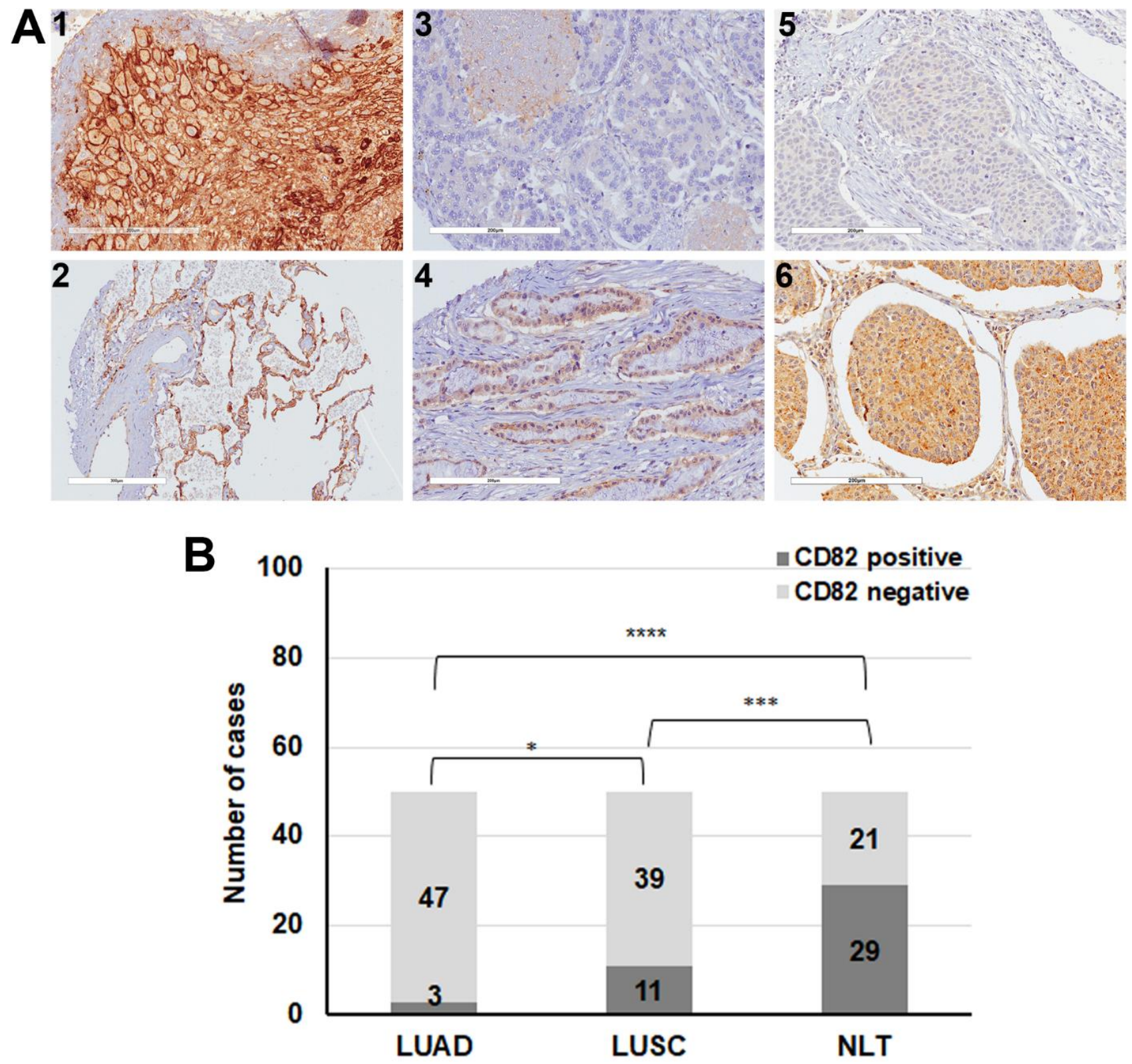

Figure 4. Expression CD82/KAI1 expression in normal and tumour human lung tissue samples. (A) Analysis of CD82 expression in normal human lung tissue (NLT) $(n=50)$ and patient-derived human LUAD $(n=50)$ and LUSC $(n=50)$ tissue microarrays (TMAs) by immunohistochemistry. 1 Placenta tissue sample used as a positive control for CD82 expression. 2 Normal human lung tissue showing expression of CD82 localised in the plasma membrane of lung epithelial cells, 3 LUAD negatively stained for CD82. 4 LUAD exhibiting cytoplasmic staining of CD82 in the tumour cells. 5, 6, LUSC negatively and positively stained for CD82, respectively. (Scale 1, 3, 4, 5, 6, $200 \mu \mathrm{m}$, and 2, $300 \mu \mathrm{m}$ ). (B) Statistical analysis of CD82 expression in TMAs of normal human lung tissue and in lung tissues of patients with LUAD and LUSC by Fisher's exact test $\left({ }^{*} p<0.05,{ }^{* * *} p<0.001,{ }^{* * * *} p<0.0001\right)$. 
A

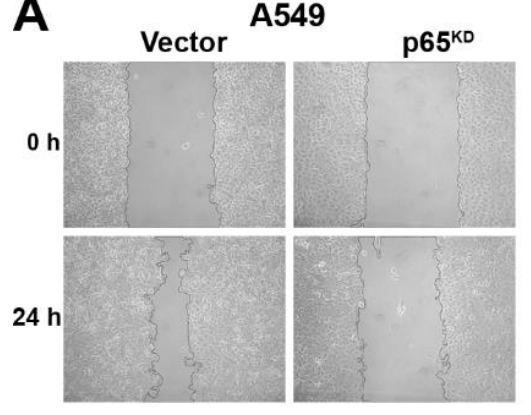

B

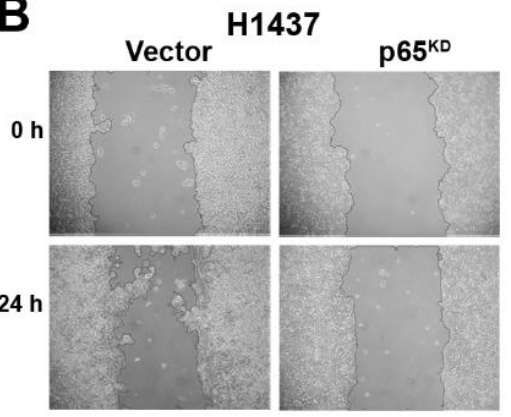

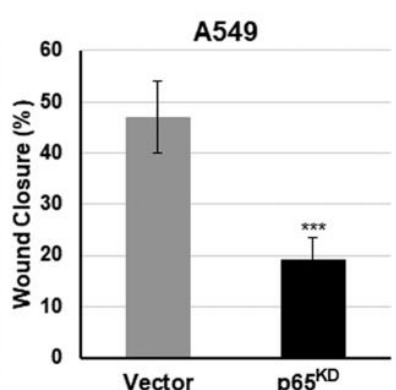

C

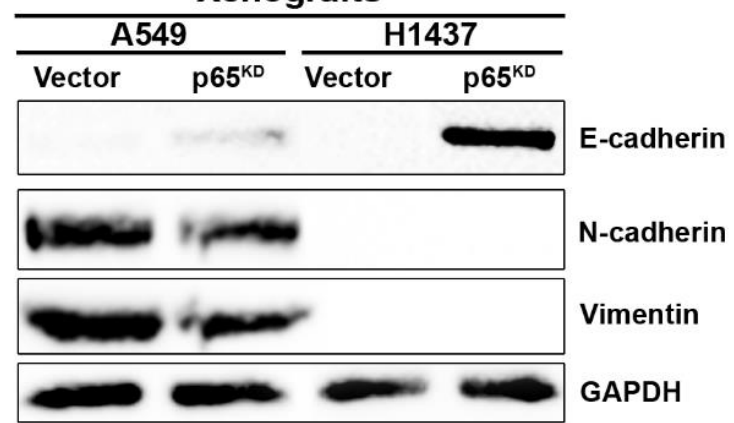

D

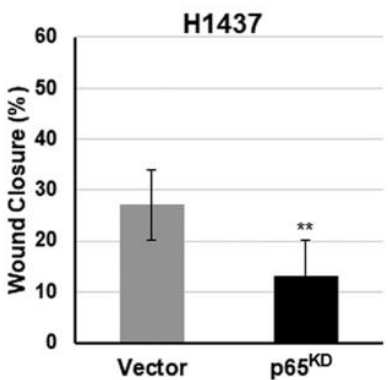

Cells

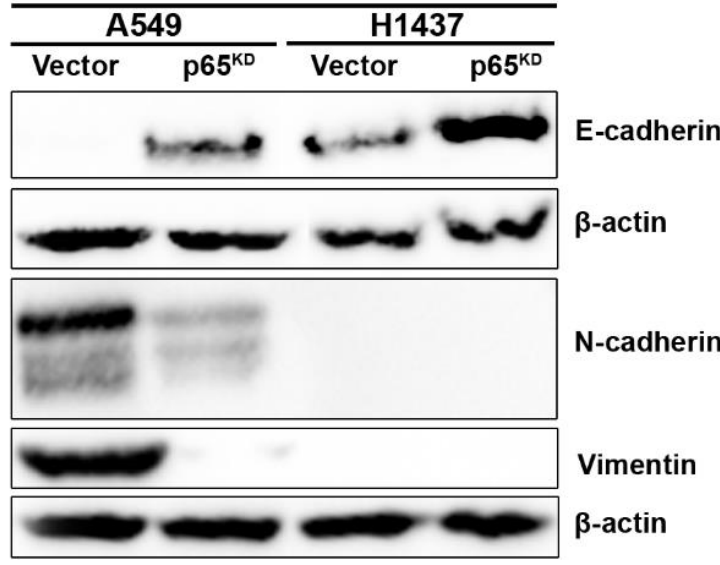

Figure 5. Loss of p65 reduces cell migration and enhances the expression of an epithelial cell phenotype. (A,B) In confluent monolayer cultures of vector control and p65 ${ }^{\mathrm{KD}}$ A549 and $\mathrm{H} 1437$ human lung cancer cells a scratch was generated, and the cells were allowed to heal the wound by establishing new cell-cell contacts. (C,D) Loss of RelA/p65 enhances the epithelial phenotype. Total protein lysates were extracted from vector control and p65 ${ }^{\mathrm{KD}}$ A549 and H1437 cancer cells either grown as tumours in in vivo xenografts in NSG mice (C) or cultured as monolayers in vitro (D), and analysed by immunoblotting for the expression of E-cadherin, $\mathrm{N}$-cadherin and vimentin or GAPDH and $\beta$-actin as a reference control. The panels in Figure 5D resulted from the joining of strips of different blots. For all quantification analysis raw, unprocessed images were used. ${ }^{* *} p<0.01,{ }^{* * *} p<0.001$.

The reduction in cell migration prompted us to investigate the effects of p65 on the expression of the epithelial cell phenotype. Loss of an epithelial phenotype in cancer is observed during an epithelial-to-mesenchymal cell transition (EMT), a hallmark of cancer detected in metastasising cancer cells. EMT is characterised by the expression of certain biomarker proteins such as loss of the epithelial cell marker E-cadherin and increased expression of mesenchymal cell markers such as $\mathrm{N}$-cadherin and vimentin [45-50].

Canonical NF-KB was shown to regulate EMT at several levels [50-55]. Hence, we investigated if loss of p65 affected the expression of both epithelial and mesenchymal cell markers. Loss of RelA/p65 resulted in the induction of E-cadherin expression in both A549 and H1437 cells and in the suppression of N-cadherin and vimentin in A549 cells in both cells grown as tumour xenografts (Figure 5C), or cultured as monolayers (Figure 5D). H1437 cells expressed undetectable levels of N-cadherin and vimentin, under our growth conditions, in agreement with previous studies [56,57]. The expression and localisation of E-cadherin were also investigated by immunofluorescence in vector and RelA/p65 ${ }^{\mathrm{KD}}$ H1437 cells. Loss of RelA/p65 resulted in a marked increase in cell surface expression of E-cadherin compared to their control counterparts (Figure S6). 


\subsection{Downregulation of p65-Reduced Cell Migration and EMT Was Due to Induction of CD82}

CD82 has been shown to act as a metastasis suppressor through various mechanisms [39,41,58], and since RelA/p65 ${ }^{\mathrm{KD}}$ cells exhibit reduced cell migration and an enhanced epithelial phenotype, we investigated the impact of CD82 on cell migration and EMT. We generated CD82-overexpressing A549 and H1437 cancer cells by transfection with either a control mCherry expression vector or the same vector carrying CD82 fused to mCherry (mCherry-CD82 ${ }^{\mathrm{OE}}$ ) $[59,60]$, followed by selection in G418 and FACS sorting. CD82 expression was verified by immunoblotting using a mCherry-specific antibody. A $45 \mathrm{kDa}$ mCherry protein was detected in the mCherry vector control cells, whereas a $70 \mathrm{kDa}$ protein was detected in the mCherry- $\mathrm{CD} 82^{\mathrm{OE}}$-transfected cells due to mCherry-CD82 protein fusion. Higher, heterogeneous molecular weight CD82 proteins detected were most likely due to N-linked glycosylations involved in CD82 functions [61,62] (Figure 6A). Importantly, expression and localisation of the fused mCherry-CD82 protein was detected in the plasma membrane of the mCherry-CD82 ${ }^{\mathrm{OE}} \mathrm{A} 549$ and $\mathrm{H} 1437$ cells as visualised by fluorescence microscopy (Figure 6B). CD82 did not significantly affect the proliferation of mCherry-CD82 ${ }^{\mathrm{OE}}$ A549 and H1437 cells compared to their vector control counterparts (Figure S7).

Next, we performed a scratch assay to measure the impact of CD82 on cell migration in vitro. Overexpression of CD82 in cancer cells markedly reduced their migration ability / capacity compared to mCherry-vector control A549 (Figure 6C) and H1437 (Figure 6D) cells.

We also analysed the specific expression of epithelial and mesenchymal cell markers, by immunoblotting (Figure 6E,F). CD82 ${ }^{\mathrm{OE}}$ resulted in the induction of E-cadherin expression in both A549 and H1437 cells and in the suppression of N-cadherin and vimentin in A549 cells (Figure 6E,F). H1437 cells expressed undetectable levels of N-cadherin and vimentin, (Figure 6F).

To further confirm our results that the effects of $\mathrm{p} 65^{\mathrm{KD}}$ on the expression of the epithelial cell phenotype were mediated through CD82, we knocked-down the expression of CD82 in RelA/p65 $\mathrm{KD}$ A549 cancer cells (Figure 6G) using the control retroviral vector pSIREN-ZsGreen or pSIREN-ZsGreen-shCD82 [63] (Figure S8). The simultaneous downregulation of p65 and CD82 was verified by immunoblotting in the double-transfected cells (Figure 6G). Total protein lysates from $\mathrm{A} 549$ vector control, p65 ${ }^{\mathrm{KD}}$ and $\mathrm{p} 65^{\mathrm{KD}} / \mathrm{CD} 82^{\mathrm{KD}}$ cells were also analysed for the expression of E-cadherin, $\mathrm{N}$-cadherin and vimentin. Downregulation of $\mathrm{CD} 82$ in $\mathrm{p} 65^{\mathrm{KD}}$ cells was able to restore $\mathrm{N}$-cadherin protein expression levels and to a lesser extent the expression levels of E-cadherin and vimentin indicating that p65 acts in favour of EMT progression in part through downregulation of CD82.

\subsection{RelA/p65 ${ }^{K D}$ Impaired Integrin-Mediated Signalling Involving ERK, Akt and Rac1}

The downregulation of E-cadherin and the reduced cell migration in the absence of RelA/p65 prompted us to investigate the engagement of signalling pathways by bioinformatics using the NCI-Nature pathway analysis. A link between NF-kB RelA/p65, CD82 and integrin signalling pathways was revealed. The analysis identified similarly affected pathways in both cell lines, A549 and H1437. For example, in the biological processes, 9.3\% and $5.7 \%$ of genes of the entire cohort, for A549 and H1437, respectively, were involved with the immune responses (Figure 7Aa,c). In the biological pathways, genes involved in integrin interactions and epithelial-to-mesenchymal transition were affected (Figure 7Ab,d), and the involvement of integrin-mediated signalling was also verified (Table S2). 
A

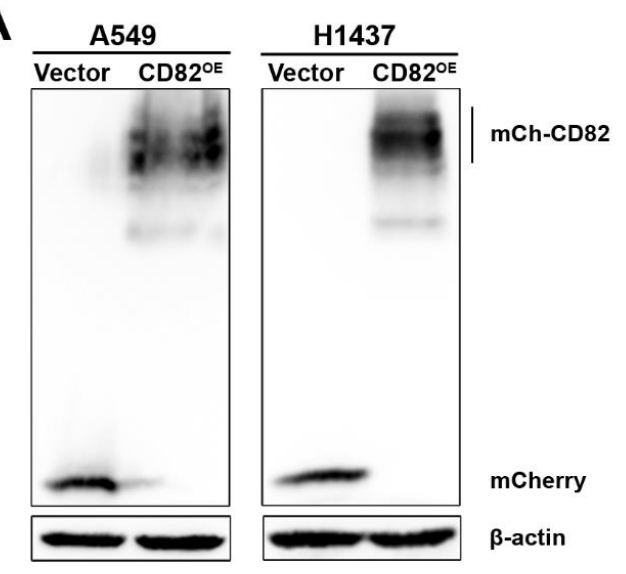

B

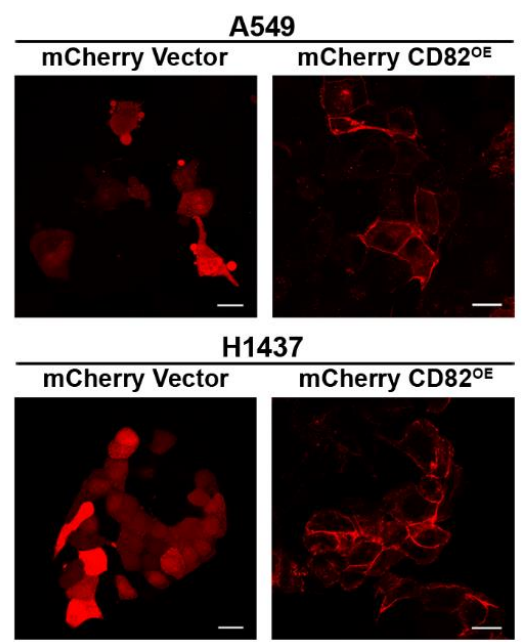

C
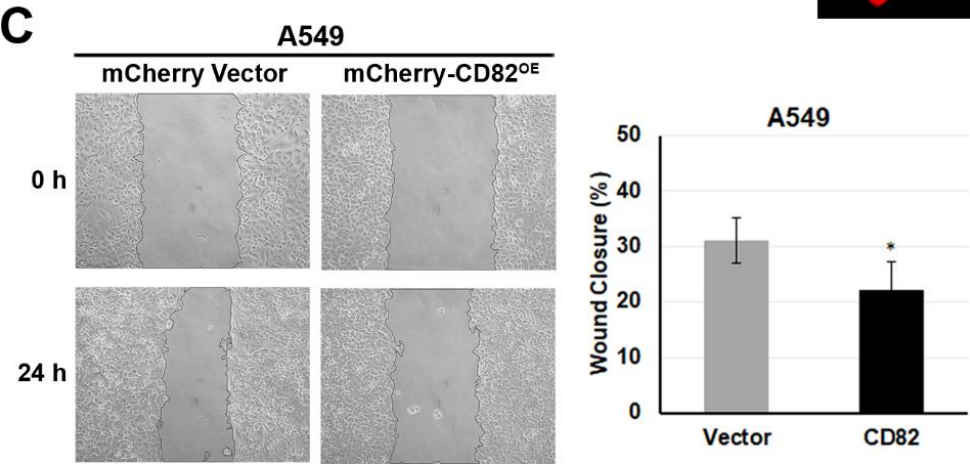

E

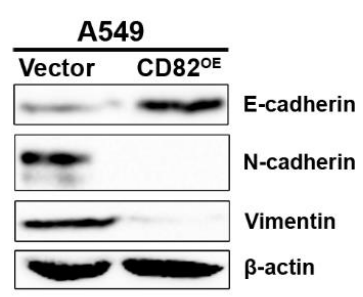

D
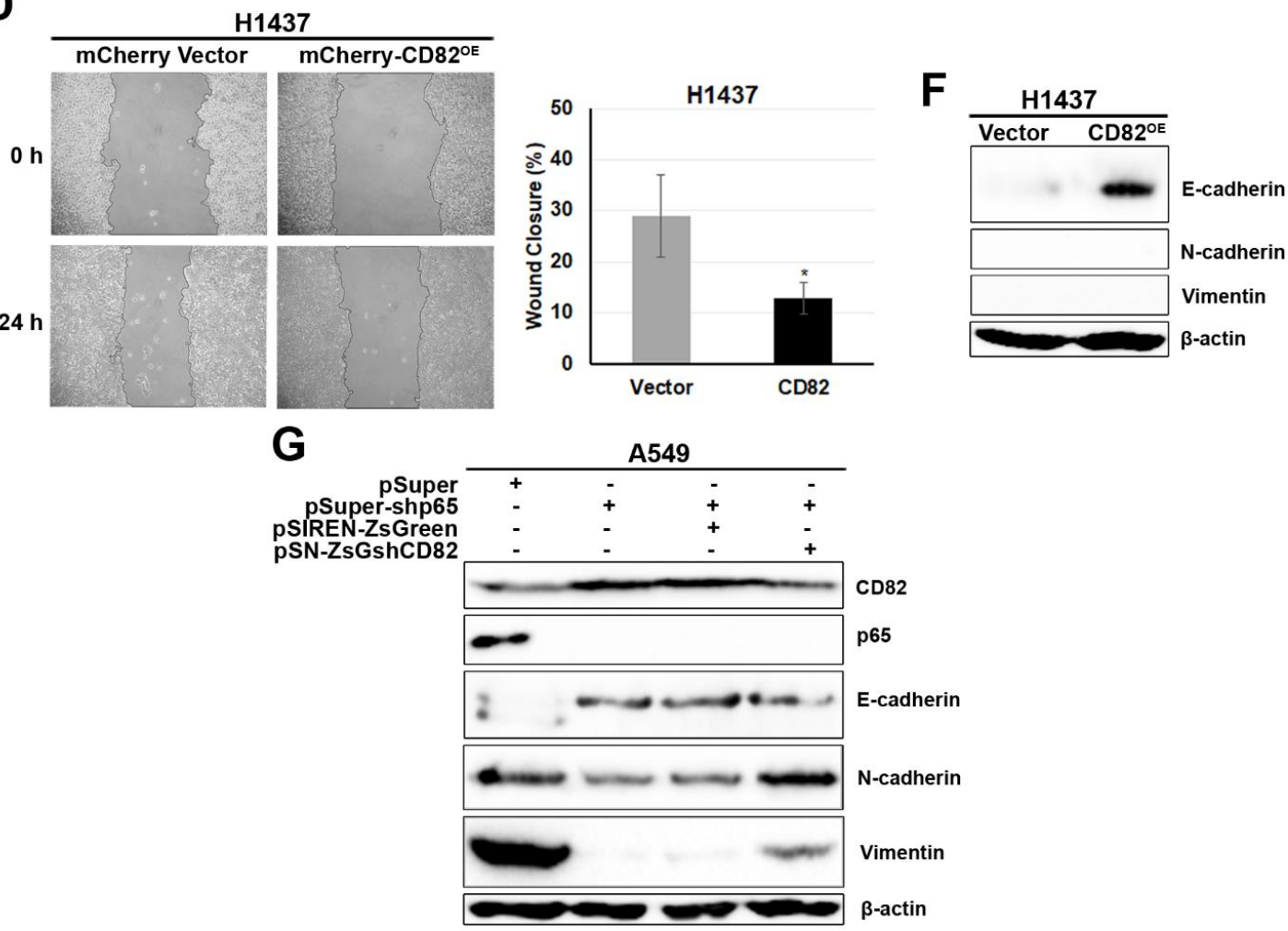

Figure 6. Effects of p65 and CD82 on cell migration and the expression of EMT markers in human lung cancer cells. (A) Generation of CD82-overexpressing human lung cancer cells. Control mCherry and mCherry-CD82 ${ }^{\mathrm{OE}}$ (mCh-CD82 ${ }^{\mathrm{OE}}$ ) vectors were transfected in A549 and H1437 cells following selection in G418 to generate stable cell populations overexpressing the mCherry-CD82 fusion protein. (B) Cytoplasmic localisation of mCherry protein in vector control mCherry cells compared to membrane localisation in mCh-CD82 ${ }^{\mathrm{OE}} \mathrm{A} 549$ and $\mathrm{H} 1437$ cells detected by fluorescence microscopy. (C,D) In confluent 
monolayers of mCherry vector control and mCherry-CD82 ${ }^{\mathrm{OE}}$ in A549 (C) and H1437 (D) cells, a scratch was generated and the cells were allowed to heal the wound by establishing new cell-cell contacts. The percent of wound closure was estimated and presented as bar graphs on the right-hand side of (C,D) for A549 and H1437 cells, respectively ( $p<0.05$ by Student's $t$ test, bars represent $\pm S D)$. (E,F) Overexpression of CD82 $\left(\mathrm{CD} 82^{\mathrm{OE}}\right)$ enhances the epithelial phenotype. Total protein lysates were extracted from vector control and CD82 ${ }^{\mathrm{OE}} \mathrm{A} 549$ (E) and $\mathrm{H} 1437$ (F) cancer cells and analysed by immunoblotting for the expression of E-cadherin, $\mathrm{N}$-cadherin and vimentin or $\beta$-actin as a reference control. (G) p65 ${ }^{\mathrm{KD}}$ A549 cancer cells were infected with either the control retroviral vector or a vector carrying a ShCD82. The retroviral vectors used were the control pSIREN-ZsGreen or pSIREN-ZsGreen-shCD82 (pSN-ZsG-sh82) expressing a CD82-specific shRNA in addition to fluorescence protein ZsGreen, as indicated at the top. Total protein lysates were extracted and analysed by immunoblotting for the expression of CD82, p65, and for the epithelial and mesenchymal cell markers E-cadherin, N-cadherin and vimentin, or $\beta$-actin as a reference loading control.

A

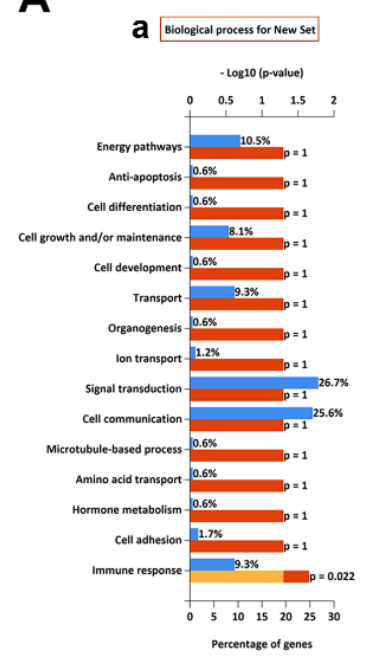

A549

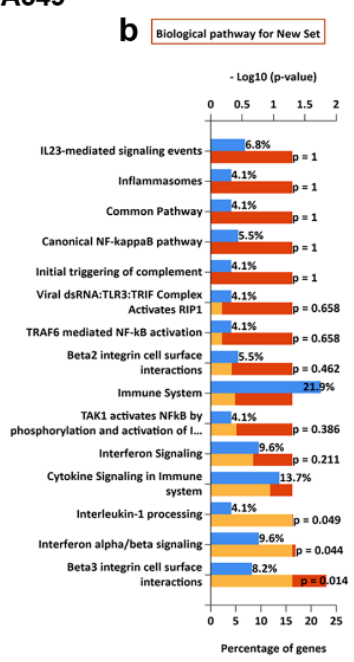

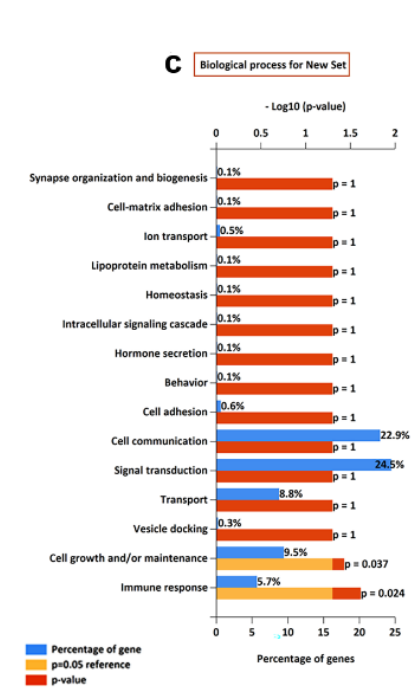

H1437

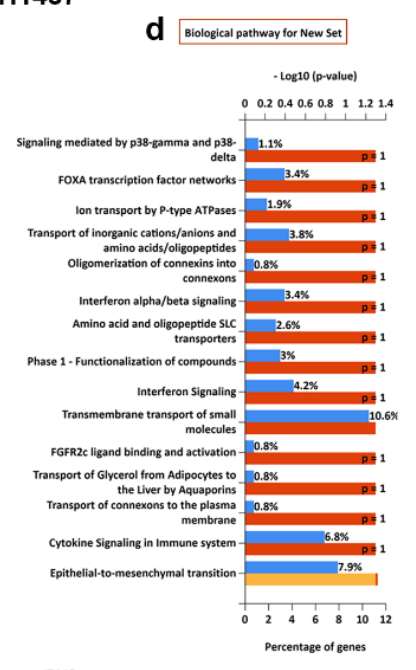

H1437

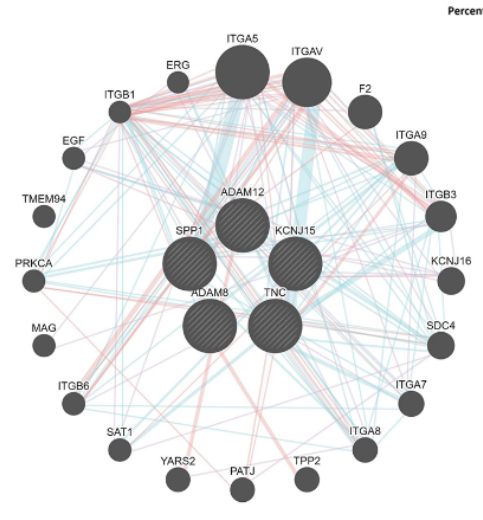

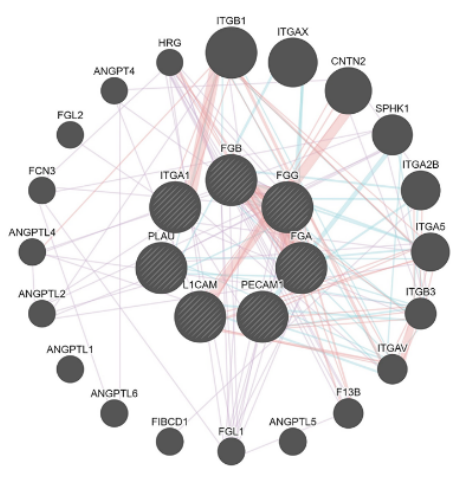

B

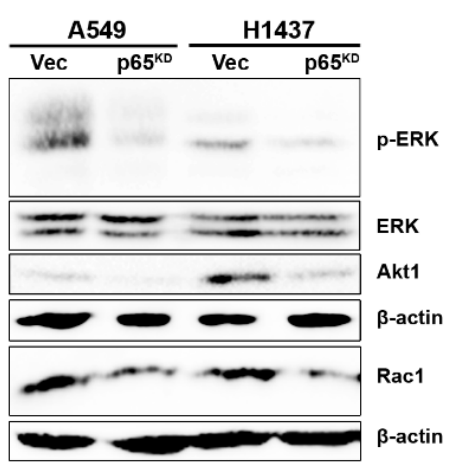

Figure 7. Effects of p65 on integrin-mediated signalling in human lung cancer cells. (A) Bioinformatics analysis of NF- $\mathrm{B}$ RelA/p65-regulated genes involved in a particular pathway. Panels $(\mathbf{a}, \mathbf{b})$ show the biological processes and the percentage 
of genes of the entire cohort involved in a particular process. Panels (c,d) show the biological pathways affected. The analysis of all genes in the human A549 and H1437 NSCLC cell lines revealed that genes involved in immune response, integrin pathways and epithelial-to-mesenchymal cell transition were affected. The red/yellow bars represent the $p$-value. The more yellow, the more significant the enrichment. The role of the enrichment is to identify processes that can be potentially altered based on all differentially expressed genes. All genes involved in integrin pathways for A549 and H1437 and for " $\alpha 9 \beta 1$ integrin signalling events" were used to model gene-gene interactions revealing an interesting crosstalk. (B) Expression of protein molecules involved in integrin-mediated signalling, such as ERK, phospho-ERK, Akt1 and Rac1 in vector control and p65 ${ }^{\mathrm{KD}}$ A549 and H1437 human lung cancer cells.

Based on these data, next we investigated the expression of several protein molecules involved in integrin-mediated signalling [64] in vector control and p65 ${ }^{\mathrm{KD}} \mathrm{A} 549$ and H1437 human lung cells. Loss of Rel/p65 in both A549 and H1437 cell lines resulted in the downregulation of phospho-ERK, Akt1 and Rac1 downstream signalling molecules (Figure 7B), in agreement with the bioinformatics analysis (Figure 7A and Table S2).

\section{Discussion}

Canonical NF- $\kappa B$ signalling components such as the IKK $\beta$ kinase and RelA/p65 have been shown to act as tumour promoters in several models of NSCLC. These include the chemical carcinogen urethane-induced NSCLC model in mice $[25,26]$ and the oncogeneinduced NSCLC, such as mutant oncogenic KRAS [11-14] and EGFR [15-17], both in mouse NSCLC transgenic models and in human NSCLC cell lines transplanted in immunecompromised mice.

Human NSCLC is initiated by tumour-initiating cells (TICs) bearing specific mutations giving rise to different histological subtypes such as LUAD and LUSC $[3,4,6]$. Using genetic approaches to inducibly express $K R A S^{\mathrm{G} 12 \mathrm{D}}$ in $\mathrm{CC} 10^{+}$and $\mathrm{Sftpc}^{+}$AT-II epithelial cells of the adult mouse lung, it was found that AT-II and Clara cells in the terminal bronchioles, and bronchoalveolar stem cells were identified as cells of origin for K-Ras ${ }^{\mathrm{G} 12 \mathrm{D}}$-induced lung hyperplasia and carcinomas, but only AT-II cells were identified as the predominant cell of origin of LUAD induced by K-Ras ${ }^{G 12 D}$ activation $[8,9,65,66]$. Importantly, lung cancer development and progression is also facilitated by the microenvironment surrounding the TICs. LUAD promotion is fuelled by inflammation leading in enhanced pneumonocyte proliferation [21], and it is reduced by IKK $\beta$ ablation in myeloid cells [14].

A549 and H1437 NSCLC cell lines were used to generate RelA/p65-compromised derivatives and investigate its impact on tumour growth and its mechanism(s) of action. While downregulation of RelA/p65 did not affect the proliferation of the human lung cancer cells grown as monolayers in vitro, it was required for their tumour growth in vivo grown as xenografts in immune-compromised mice (Figure 1), suggesting that RelA/p65 functions in lung epithelial cells as an NSCLC tumour promoter. In general, the rate of cancer cell proliferation in vivo is much slower than that in vitro, and tumour growth does not depend solely on cell proliferation but on several other factors including cell adaptation, stroma cell recruitment, the establishment of cell matrix interactions, the microenvironment in vivo, and to overcome species differences $[67,68]$. RelA/p65, being a regulator of a plethora of genes, may therefore regulate some of these factors and contribute to tumour growth in vivo. Our data is in agreement with the findings in urethane- and the oncogeneinduced mouse NSCLC models wherein expression of an IKB $\alpha$ SR super-repressor [11,25] or deletion of RelA/p65 [12] lead to impairment of tumour growth. Similarly, conditional deletion of IKK $\beta$ reduced cancer cell proliferation and tumour burden of adenocarcinomas in both urethane- [26] and $K R A S^{\mathrm{G} 12 \mathrm{D}}$ - [13] induced mouse NSCLC, suggesting that IKK $\beta$ was also required for LUAD development in vivo.

Transcriptome analysis of vector control and Rel/p65 ${ }^{\mathrm{KD}}$ A549 and H1437 cell tumours identified the proto-oncogene ROS1 and the LGR6 receptor gene amongst the downregulated genes, and the metastasis suppressor CD82 as one of the upregulated genes. We verified that Rel/p $65^{\mathrm{KD}}$ resulted in the downregulation of the ROS1 and in the upregulation of CD82 mRNA levels (Figure 2). 
ROS1, which encodes a receptor tyrosine kinase with no known ligands, is activated in $\sim 1-2 \%$ of NSCLC by gene rearrangements resulting in novel chimeric fusion proteins, SLC34A2-ROS and CD74-ROS [42]. However, as the human ROS1 gene promoter lacks $\kappa B$ elements and not all human lung cancer cell lines express ROS1 protein, including A549 and H1299 which are fusion-negative cell lines [69,70], we further investigated the role of CD82 [40] in epithelial lung cancer cell growth.

A few studies have identified canonical NF- $\mathrm{KB}$ targets accounting for its tumour promoting function in NSCLC. For example, an NF- $\mathrm{kB}$-regulated genetic signature identified in response to mutant EGFR oncogene inhibition in human NSCLC cells consisted of 36 genes, including the cell survival genes TNFAIP3, BIRC3 and IL-6 [16]. In a K-Ras ${ }^{\mathrm{G} 12 \mathrm{D}}$-induced LUAD mouse model, Timp1 was identified as a IKK $\beta$-mediated canonical NF-KB-regulated tumour growth regulator. Further, it was shown that activation of ERK signalling and cell proliferation required Timp1 and its receptor, the tetraspanin CD63. Knocking-down IKK $\beta$ or Timp1 reduced tumour growth in xenografts [13]. Thus, Timp1-CD63 regulates epithelial cell proliferation and apoptosis. CD82 was identified as a component of the cell surface TIMP1-interacting protein complex by directly binding to Timp1 amino-terminal region through its large extracellular loop domain and, it was shown to co-localise with Timp1 in cancer cell lines and tumour tissues. CD82 was shown to facilitate membrane-bound Timp1 endocytosis, significantly contributing to the anti-motility effects of TIMP-1 [13]. Hence, it is important to emphasise that our RelA/p65 gene signature identified CD82 involved in NSCLC growth. Although the human CD82/KAI1 gene promoter contains NF- $\mathrm{kB}$ binding sites, and NF- $\mathrm{kB}$ was shown to regulate CD82 expression with a dependency on the extracellular signals leading to the recruitment of co-activators or co-repressors [40,71-73], the mechanisms regulating CD82 transcription are still controversial [62]. Previous studies also showed that serine phosphorylated RelA/p65 can repress specific promoters, such as the tumour metastasis suppressor gene BRMS1, by recruiting the DNMT-1 methylase [74]. Anti-inflammatory responses leading to the downregulation of cytokine signalling also induce the expression of CD82 in a human lung carcinoma cell line [75].

The CD82/KAI1 metastasis suppressor gene encodes tetraspanin TSPAN27, a transmembrane glycoprotein that is a member of the transmembrane 4 superfamily. It regulates T-cell signalling through the T-cell receptor (TCR). It associates with CD4 or CD8 and delivers costimulatory signals for the TCR/CD3 pathway. Expression of CD82 is downregulated during tumour progression of human cancers [39-41,62]. CD82 expression was markedly decreased in LUAD and LUSC versus normal lung tissue, but more profoundly in the former (Figure 4). The transition from normal or benign stage to a malignant stage was accompanied by a profound reduction in the expression of CD82; but loss of CD82 expression appeared to be independent of disease progression, which was also confirmed by bioinformatics analysis of the data sets TCGA and GTEX (Figure S2), in agreement with previous studies [39-41,62,76]. CD82 did not appear to be a valid biomarker of overall survival, although low CD82 expression in LUAD appeared to be associated with poorer survival (not shown). Because CD82 acts as a metastasis suppressor and interacts with CD8, although we showed that CD8 ${ }^{+}$TILs were increased in CD82 negative tumours, this difference was not statistically significant, suggesting that the suppressing activity of CD82 may not be related to the recruitment of $\mathrm{CD}^{+}$TILs (Figure S4 and Table S1).

The progression of cancer cells to invasive, metastatic cells involves an "invasionmetastasis" cascade and the activation of the EMT programme. This is associated with the loss of an epithelial cell phenotype and the acquisition of a mesenchymal cell-like cell phenotype, which is crucial for cancer cell migration, the invasion of adjacent tissues and metastasis, that is dissemination via the circulation into distant tissues/organs and colonisation [45-48]. The metastatic process is fuelled by inflammation, a hallmark of cancer, leading to the activation of canonical NF- $\mathrm{KB}$, a major regulator of pleiotropic EMTinducing transcription factors (EMT-TFs), such as Snail/SNAI1, Slug/SNAI2 and Twist [50]. Activation of the EMT-TFs leads to the loss of the epithelial cell marker E-cadherin, and the induction of the expression of mesenchymal cell proteins, such as N-cadherin, vimentin, fi- 
bronectin, and matrix metalloproteinases (MMPs) [46,50]. Integrins are transmembrane proteins which interact with both extracellular matrix and intracellular cytoskeletal molecules, and activate several signalling pathways involved in cell adhesion, motility and growth, and promote tumour metastasis [64]. EMT and cell migration can also be promoted by integrin signalling which activates Rac1 and canonical NF- $\mathrm{kB}$ signalling [64].

We showed that loss of p65 reduced cell migration and enhanced the expression of the epithelial cell marker E-cadherin, and decreased the expression of the mesenchymal cell markers, N-cadherin and vimentin (Figure 5 and Figure S5), an effect mediated, in part, by CD82 in support of its metastasis suppressor function, since forced expressions of CD82 suppressed cell migration and EMT (Figure 6), in agreement with previous studies [77-79].

Bioinformatics analysis linked p65-CD82 to integrin signalling (Figure 7 and Table S2). Previous studies showed that CD82 interacts with many membrane proteins and acts to suppress metastasis via several different mechanisms [39-41,62]. CD82 was shown to physically interact with other proteins and also to indirectly affects critical signalling pathways through phosphorylation-mediated activation of proteins. It was shown that CD82 associates with the EGFR and integrins, including $\alpha 3, \alpha 4, \alpha 5, \alpha 6$ and $\beta 1$ accelerating their co-internalisation and resulting in reduced cell migration $[39,40,58,59,76,80,81]$. CD82 expression was also associated with decreased $\beta$-catenin degradation, leading to its accumulation at the plasma membrane and the stabilisation of cell surface E-cadherin- $\beta$ catenin complexes which promote cell-cell adhesion and restrain metastasis $[58,82]$. This is interesting as a $\beta$-catenin/Reptin complex was found to represses CD82 transcription and also NF- $\mathrm{kB}$ activation [73], suggesting the existence of a feed-forward mechanism whereby an increase in $\beta$-catenin inhibits CD82 expression to enhance Wnt signalling and cancer metastasis $[40,83]$.

We investigated several downstream effector molecules of integrin-mediated signalling and showed that loss of RelA/p65 results in the downregulation of phospho-ERK, Akt1 and Rac1 involved in cell proliferation, survival and motility [64,80]. Thus, p65-CD82 functions by suppressing integrin-mediated EMT, cell migration and tumour growth. The metastasis suppressor function of CD82 was first documented in a rat prostate cancer model [84], and also in a murine orthotopic lung cancer model [85], and in several other cancer cell models including hepatocarcinoma, melanoma, sarcoma, pancreatic and breast cancer affecting in vivo invasion and metastasis [40]. The tumour suppressive actions of CD82 are due to several different mechanisms, including interference with integrinmediated signalling through direct interactions with integrin subunits [39], but also by indirectly affecting other signalling pathways [39,86].

The changes in the EMT programme and cell migration associated with the loss of RelA/p65, in conjunction with the changes expression of several cell surface genes may be related to the plasticity cell states recently described in human LUAD tumours [8,9]. This is further supported by our finding that LGR6 was downregulated upon loss of RelA/p65, most likely resulting in the suppression of $\mathrm{Wnt} / \beta$-catenin signalling implicated in the induction of cancer stem cells and metastasis, suggesting that this may be another mechanism by which canonical NF- $\mathrm{kB}$ modulates Wnt signalling, cancer stem cell expansion and metastasis of lung cancer cells $[37,38]$. Importantly, CD82 suppresses $\beta$-catenin-mediated Wnt signalling activation and significantly reduces $\beta$-catenin levels through the exosomal clearance of $\beta$-catenin $[40,87]$.

Collectively, these data support our RelA/p65 gene signature in human lung cancer cells, and provides a mechanism by which canonical NF- $\mathrm{kB}$ signalling contributes to NSCLC development and progression.

\section{Materials and Methods}

\subsection{Cell Culture}

Normal human lung fibroblasts (HDFs), HFL-1 and MRC-5 [88-90] and the human NSCLC cells A549 (K-Ras ${ }^{\mathrm{G} 12 \mathrm{~S}}$, p53 ${ }^{\mathrm{wt}}$ ) were cultured in low glucose Dulbecco's modified Eagle medium (DMEM), and H1437 (K-Ras ${ }^{\mathrm{wt}}$, p53 ${ }^{\mathrm{R} 247}$ ) in RPMI-1640 [26]. The retrovirus 
packaging cell line, Phoenix, was cultured in high glucose DMEM (Sigma-Aldrich Chemical Co., St. Louis, MO, USA). All culture media were supplemented with $10 \%$ foetal bovine serum (Gibco-Thermo Fisher Scientific, Waltham, MA, USA), 2 mM L-glutamine, 100 units $/ \mathrm{mL}$ penicillin and $100 \mu \mathrm{g} / \mathrm{mL}$ streptomycin (Biowest, Nuaillé, France). Cells were incubated at $37^{\circ} \mathrm{C}, 5 \% \mathrm{CO}_{2}$.

\subsection{DNA Transfections}

A549 and H1437 cells were transfected with the plasmid vectors pSuper-Puro (pSPuro) and pSuper-Puro-shp65 (pS-Puro-shp65) [28,29] using polyethilenimine (PEI linear, MW25000; Polysciences Europe GmbH). For the overexpression of CD82, A549 and H1437 cells were transfected with the plasmid vectors mCherry-C1 and mCherry-CD82 ${ }^{\mathrm{OE}}[59,60]$. Briefly, $4 \mu \mathrm{g}$ of plasmid DNA was mixed with $30 \mu \mathrm{g}$ PEI in $100 \mu \mathrm{L}$ serum- and antibioticfree DMEM and incubated for $10 \mathrm{~min}$ at room temperature, and then added to $70 \%$ confluent cells for $24 \mathrm{~h}$. The transfection medium was removed, the cells were washed twice with serum-free DMEM and incubated for another $24 \mathrm{~h}$ before applying selection in $3 \mu \mathrm{g} / \mathrm{mL}$ puromycin for 10 days to generate stable RelA/p65 knockdown (RelA/p65 ${ }^{\mathrm{KD}}$ ) cell lines $[26,88]$. For the stable generation of $\mathrm{CD} 82^{\mathrm{OE}}$ cell lines, the transfected cells were selected in $500 \mu \mathrm{g} / \mathrm{mL}$ G418 followed by sorting based on red fluorescence.

\subsection{Retroviral Vectors and Infections}

The retroviral vectors used were the control pSIREN-RetroQ-ZsGreen (pSIRENZsGreen) and pSIREN-RetroQ-ZsGreen-shCD82 (pSIREN-ZsGreen-shCD82) expressing a CD82-specific shRNA [63]. Cells were infected with high-titre control retroviruses or carrying shCD82, generated following transfection of amphotropic phoenix cells [89,90]. Polyclonal populations of stable retroviral transduced cells were obtained by GFP selection.

\subsection{Assessment of Cell Proliferation and Apoptosis of Human Lung Cells}

Equal number of control vector and $\mathrm{p} 65^{\mathrm{KD}}$ cells were plated in 24-well plates and monitored by the IncuCyte-ZOOM ${ }^{\circledR}$ Live-Cell Analysis System (Sartorius, Michigan, MI, USA) for $92 \mathrm{~h}$ to construct growth curves using the IncuCyte ${ }^{\circledR}-\mathrm{ZOOM}$ software.

Cell apoptosis was assessed by Annexin V-FITC/PI staining kit (Biolegend \#640914, San Diego, CA, USA) according to the manufacturer's instructions, and analysed with a fluorescence activated cell sorter (BD FACSAria III, BD Biosciences, San Jose, CA, USA). The percentages of early (Annexin $\mathrm{V}^{+}$) and late (Annexin $\mathrm{V}^{+} / \mathrm{PI}^{+}$) apoptotic cells in each group were determined and represented in bar graphs.

\subsection{Luciferase Assays}

For NF- $\mathrm{BB}$ luciferase reporter assays, cells were seeded at $60 \%$ confluent in 12 -well plates and transfected with Polyethylenimine (PEI) (Polysciences Europe GmbH). The NF- $\kappa$ B luciferase reporter assays were performed using the Dual-Luciferase Reporter Assay System (Promega E1910) which measures sequentially the activities of firefly (Photinus pyralis) and Renilla (Renilla reniformis or sea pansy) luciferases from a single sample. Briefly, cells were transiently transfected with $0.3 \mu \mathrm{g} /$ well of a luciferase reporter plasmid pGL3, pCMV-Luc (Addgene \#45968, Watertown; MA, USA) or pGL3-5x $\kappa B$ carrying the firefly luciferase gene and $0.3 \mu \mathrm{g} /$ well $\mathrm{pRL}-\mathrm{TK}$ plasmid carrying the renilla luciferase gene. Twenty-four hours after transfection, cells were lysed and luciferase activity was assayed using Dual-Luciferase Reporter Assay System kit according to manufacturer's instructions (Promega Co., Madison, WI, USA). Relative luciferase activities are expressed as fold induction. All the experiments were performed in triplicates and the average is shown in each figure.

\subsection{Human NSCLC Xenograft Models}

For human NSCLC models, NSG (NOD-SCID-IL2Rgamma) mice were used. The NOD.Cg-Prkdc ${ }^{\text {scid }}$ Il2rg ${ }^{\text {tm1Wjl }} /$ SzJ (Stock: 005557, NSG) mice were purchased from the 
Jackson Laboratory (Bar Harbor, ME USA) and bred in-house in pathogen-free conditions according to the protocols approved by the BRFAA Institutional Animal Care and Use Committee. Mice were kept under 12-h light:12-h dark conditions with free access to food and water. All food, cages, water, and other items that came in contact with mice were sterile.

Control and RelA/p65 ${ }^{\mathrm{KD}}$ A549 and H1437 cancer cells were subcutaneously inoculated into either side of immune-compromised 5-week-old male NSG (NOD-SCIDIL2Rgamma) mice (left side for WT and right side for KD cells) and were allowed to grow in vivo as tumour xenografts. Nine mice $(n=9)$ were studied per cell line. The mice were sacrificed at the end of 4 weeks for tumour weight measurement and for histopathologic and molecular analysis of the tumours [26]. Briefly, part of the tumours was fixed in 10\% buffered formalin overnight, then transferred to $70 \%$ ethanol, and embedded in paraffin. Five-micrometre sections were cut and used for immunohistochemical analysis. A second part of the tumours (50-100 mg) was snap-frozen in liquid nitrogen and processed for molecular studies. All mice were housed in pathogen-free conditions according to the protocols approved by the BRFAA Institutional Animal Care and Use Committee.

\subsection{RNA-Sequencing and Analysis}

Unbiased RNA-Seq analysis was performed in three biological replicates per each cell line [26]. Briefly, total RNA quantity of the samples was measured with Nanodrop, while quality and integrity were verified with Agilent bioanalyser RNA 6000 nano kit. RNA-seq libraries were prepared with the Illumina TruSeq RNA v2 kit with $1 \mu \mathrm{g}$ of total RNA input. QC of the RNA-Seq Libraries was performed with Agilent bioanalyser DNA1000 kit and quantification with Qubit HS. 75-bp single-end reads were generated with the Illumina NextSeq500 sequencer. RNA-seq analysis was performed, using first of all the quality control program FastQC (https://www.bioinformatics.babraham.ac.uk/projects/fastqc/, accessed on 20 July 2018. Quality scores across all bases and across all samples were good. After checking the quality, we used the tool tophat2 with standard parameters for alignment. Hg19 reference genome was used. Samtools was then used to sort and filter the above, in order to get significant results. Last step to get the differential expression was to use cuffdiff with standard parameters. For GO analysis we used the online databases: David and EnrichR (https:/ / david.ncifcrf.gov, accessed on 14 October 2020; https:/ / maayanlab.cloud/Enrichr/, accessed on 19 October 2020). For GO analysis we used the online databases: David and EnrichR (https:/ / david.ncifcrf.gov, https:/ / maayanlab.cloud/Enrichr/, accessed on 19 October 2020). In R studio we utilised heatmap in order to produce the heatmaps. The Venn diagrams were produced from an online tool called meta-chart (https:/ / www.meta-chart.com/venn, accessed on 31 July 2020).

\subsection{Quantitative Real-Time PCR ( $q$ RT-PCR)}

Total RNA from human lung cancer cell lines and from tumours grown in NSG mice was isolated using the TRI-Reagent (Merck, Kenilworth, NJ, USA), according to the manufacturer's instructions. For cDNA synthesis, $0.5 \mu \mathrm{g}$ of purified RNA was reverse-transcribed using the PrimeScript ${ }^{\mathrm{TM}}$ RT reagent kit (RR037A, Takara Bio Europe, Inc., Saint-Germain-enLaye, France). For real time PCR analy-sis, $1 \mu \mathrm{L}$ of cDNAs at 1:8 dilution cDNAs were amplified using KAPA SYBR ${ }^{\circledR}$ FAST qPCR Master Mix (Kapa Biosystems, Inc., Wilmington, MA, USA) in a total volume of $10 \mu \mathrm{L}$ according to the manufacturer's instructions, in a Step One cycler (Applied Biosystems-ThermoFisher Scientific). Specific forward and reverse primers used included: CD82 forward 5'-GCTCATTCGAGACTACAACAGC-3' and reverse 5'GTGACCTCAGGGCGATTCA- ${ }^{\prime}$, ROS1 forward $5^{\prime}$-TGTCTGCTGAATGAACCCCAA- $3^{\prime}$ and reverse $5^{\prime}$-TGCCAGATCCCTGTGAATGAAA- ${ }^{\prime}$, and RPII forward $5^{\prime}$-TCAATGCTGGTTTTGGTGACG- $3^{\prime}$ and reverse $5^{\prime}$-GCATGTTGGACTCGATGCAG- $3^{\prime}$. The relative fold change in gene expression was calculated with the 2(- $\Delta \Delta \mathrm{CT})$ method us-ing RPII as reference control. Cycle threshold $(\mathrm{Ct})$ values $\geq 35$ were considered as being background. 


\subsection{Isolation of Total Proteins and Western Blot Analysis}

Cells were lysed in RIPA buffer as described previously [89,90]. Protein lysates of the mouse tumour xenografts were extracted by TRI-Reagent (Merck) according to the manufacturer's instructions. Protein samples $(40 \mu \mathrm{g})$ were analysed by SDS-PAGE followed by immunoblotting. Primary antibodies used were anti-NF-kB/p65 (sc-372), antiphospho-NF-kB/p65 (Ser536) (sc-136548), anti-CD82 (sc-1087), anti-E-cadherin (sc-8426), anti-N-cadherin (sc-89987), anti-vimentin (sc-6260), anti-mCherry (AB0040-200, Abcam Co., Cambridge, UK), anti-p-ERK (sc-7383), anti-ERK (\#9102, Cell Signalling Technology; CST, Danvers, MA, USA), anti-Akt1 (sc-5298), anti-Rac1 (\#610650, BD Transduction Laboratories), anti-GAPDH (\#2118, CST) and anti- $\beta$-actin (CloneAC15, A5441; Sigma-Aldrich Chemical Co., Milwaukee, WI, USA), followed by appropriate horseradish peroxidase (HRP)-conjugated secondary antibodies (Jackson Immunoresearch labs, UK). Immunoblots were developed using Clarity ${ }^{\mathrm{TM}}$ Western ECL Substrate (\#170-5061, BioRad Labs, Inc., Hercules, CA, USA). The chemilluminescence signal was captured with a ChemiDoc XRS Molecular Imager and protein quantification was performed using the Quantity One 1-D Analysis Software version 4.6.9 (Bio-Rad Labs, Inc., Hercules, CA, USA).

For all panels of Western blots presented, the images of protein expression were copied and pasted on a white background to make composite blots. Brightness was slightly adjusted for uniformity and clarity similarly across all samples. However, there was no image manipulation. The panels in Figure 3F and in Figure 5D resulted from the joining of strips of different blots. For all quantification analysis raw, unprocessed images were used.

\subsection{Indirect Immunofluorescence}

Indirect immunofluorescence was performed as previously described $[26,90]$. The primary antibodies used were anti-CD82 (11-559-C100, Exbio Praha, AS, Vestec, Czech Republic) and anti-E-cadherin (sc-8426) followed by appropriate Alexa Fluor 488-conjugated secondary antibodies (Jackson ImmunoResearch labs, Cambridgeshire, UK). Cells were counterstained with DRAQ5 (Invitrogen-Thermo Fisher Scientific) for nuclei visualisation. The stained cells were washed with PBS and mounted on glass slides. Images were collected on a Leica TCS-SP scanning confocal microscope with $63 \times$ objective lens.

\subsection{Tissue Sections and Immonohistochemistry}

Tissue microarrays (TMA) were made as previously described [91]. In brief cylindrical cores were extracted from donor blocks and transferred to a receiver block with a TMA roboter (TMA grandmaster, 3D histech, Budapest, Hungary). TMAs contained 50 normal human lung tissue samples $(n=50), 50$ samples from patients with LUAD $(n=50)$ and 50 samples from patients with LUSC $(n=50)$. The study was conducted according to the guidelines of the Declaration of Helsinki, and approved by the Institutional Review Board (or Ethics Committee). Informed consent of patients was given by all patients and the project was approved by the local scientific and ethics committees of the University Hospital of Ioannina, Greece (8/8-3-2019/ $\Theta 3)$ and the University Hospital of Heidelberg, Germany (\#S315/20, 12 May 2020).

Whole tumour sections from consecutive archived LUAD $(n=16)$ and LUSC $(n=13)$ surgical specimens containing tumour and nearby lung parenchyma were used for immunohistochemical analysis. Initial diagnosis was bases on typical morphological features and TTF1/p63 immunohistochemical expression.

Protein expression of CD82, CD8 and Ki67 tissue specimens: An initial pre-treatment of the tissue sections involving deparaffinisation, rehydration and heat-induced epitope retrieval (HIER) was performed in a PT Link pre-treatment system (Dako-Agilent Technologies, Inc., Santa Clara, CA, USA) using the EnVision FLEX Target Retrieval Solution (\#K8004, Dako-Agilent Technologies, Inc.) according to the manufacturer's instructions. After pre-treatment, sections were immunostained on an Autostainer Link automated immunohistochemistry system (Dako-Agilent Technologies, Inc.) according to the manufacturer's instructions. For CD82 protein expression, sections were incubated with anti- 
CD82 (11-559-C100, Exbio) at a 1:200 dilution for $20 \mathrm{~min}$, anti-CD8 (M7103, Dako) at a 1:200 dilution for $20 \mathrm{~min}$, or anti-Ki67 Clone MIB-1 (ZETA Corporation, Gunpo-city, Korea) at a 1:100 dilution for $30 \mathrm{~min}$. After immunostaining sections were counterstained with haematoxylin. Finally, sections were dehydrated, cleared and mounted. Sections were observed under an Olympus BX41 optical microscope and digitally whole slide scanned with the Aperio AT2 Leica Biosystems scanner [92].

Immunohistochemical evaluation for CD8 T cells expression was performed as previously described [93] in a semiquantitative manner: 0: no cells, 1: few cells $(<10 \%)$, 2: moderate number of positive cells $(\geq 10 \%$ and $<40 \%)$, and 3 : abundant cells $(\geq 40 \%)$, in the intra tumoural and peritumoural compartments. A binary system of low (scores 0 and 1) and high (scores 2 and 3) was used further for statistical purposed. CD82 expression was cytoplasmic and/or membranous and an at least $10 \%$ tumour cell expression was recorded as positive.

\subsection{Wound Healing}

For the wound healing assay $5 \times 10^{4}$ cells were seeded in each well of a 24-well plate, in serum-free medium. After $24 \mathrm{~h}$ linear scratch wounds were made using a sterile pipette tip. Cells were washed with PBS to remove cell debris and incubated for another $24 \mathrm{~h}$ in serum-free medium. The wounds were observed under an optical microscope and photographed at the same position at 0 and $24 \mathrm{~h}$ with a Nikon camera. The percent of wound closure was calculated with the ImageJ software and the MRI (Montpellier Resources Imagerie) wound healing tool.

\subsection{Bioinformatics Analysis}

We validated CD82 in the Cancer Genome Atlas (TCGA) data sets, Gene Expression Profiling Interactive Analysis (GEPIA) database (http:/ / gepia.cancer-pku.cn/, accessed on 27 February 2021, and UALCAN, a comprehensive and interactive web-resource for analysing cancer OMICS data (http:/ / ualcan.path.uab.edu/cgi-bin/ualcan-res.pl, accessed on 27 February 2021). The pan-cancer cohort of TCGA was downloaded through cBioPortal (https: / / www.cbioportal.org/, accessed on 27 February 2021). Single cell analysis took place using the Single Cell Portal (https: / / singlecell.broadinstitute.org/single_cell, accessed on 27 February 2021).

\subsection{Statistical Analysis}

Numerical data are presented as mean of at least three independent experiments and bars represent \pm SD. Statistical differences showed in graphs were calculated using Student's $t$ test or chi-square test as indicated in figure legends using the GraphPad Prism 5 software. $p$-values of $<0.05$ were considered statistically significant.

\section{Conclusions}

NF-кB RelA/p65 promotes lung epithelial cell tumour growth in vivo by downregulating the metastasis suppressor CD82 and enhancing the epithelial-to-mesenchymal cell transition via integrin-mediated signalling involving the mitogenic ERK, Akt1 and Rac1 proteins.

Supplementary Materials: The following are available online at https: / www.mdpi.com/article / 10.3390 / cancers13174302/s1: Figure S1. NF-кB luciferase reporter assays of A549 and H1437 cells. Figure S2. Growth of vector control and p65 ${ }^{\mathrm{KD}}$ A549 and H1437 cells. Figure S3. Expression of CD82 in LUAD and LUSC. Figure S4. Analysis of the immunohistochemical expression of CD8 in whole sections of early and advanced human LUAD and LUSC. Figure S5. Single cell analysis of human immune cells in lung cancer. Figure S6. Expression and localisation of E-cadherin protein in vector control and RelA/p65 ${ }^{\mathrm{KD}} \mathrm{H} 1437$ human NSCLC cell line. Figure S7. Growth curves of vector control mCherry and mCherry-CD82 ${ }^{\mathrm{OE}}$ A549 and H1437 lung cancer cells. Figure S8. Generation of CD82 ${ }^{\mathrm{KD}}$ human NSCLC cells. Table S1. Clinicopathological variables and statistical analysis of the immunohistochemical staining of CD8, a marker of TILs, in FFPE whole tissue sections from NSCLC 
patients. Table S2. Bioinformatics analysis revealed a link between NF-kB RelA/p65, and integrin signalling pathways.

Author Contributions: E.R.: data curation, formal analysis, validation, investigation, visualisation, methodology and writing-original draft. E.C.: data curation, formal analysis, validation, investigation, visualisation and methodology. G.K.: data curation, formal analysis, validation, investigation and methodology. G.V.: data curation, formal analysis, validation, investigation and methodology. D.C.: data curation, software, formal analysis, investigation and methodology. A.M.: resources and methodology. J.M.G.: resources, methodology and draft writing. K.K.: resources, data curation, formal analysis, investigation and methodology. M.K.: resources, data curation, formal analysis, investigation and methodology. A.B.: resources and methodology. A.G.: formal analysis, validation, investigation, visualisation and methodology. K.B.M.: consultation and writing original draft. E.K. (Emmanouil Karteris): software, formal analysis, validation, investigation and methodology. A.K.: resources, supervision, investigation, visualisation and methodology. E.K. (Evangelos Kolettas): conceptualisation, supervision, funding acquisition, project administration and writing - original draft review and editing. All authors have read and agreed to the published version of the manuscript.

Funding: This research has been funded by an Institutional Program Grant for the Development of Research Institutes "Advanced research activities in biomedical and agro-alimentary technologies, ARABAT (BITAD)" (MIS5002469) of the operational program "Competitiveness, Entrepreneurship and Innovation" (NSRF2014-20, EU-ERDF) (EK), a research grant in Biomedical Sciences from FONDATION SANTÉ (EK), a STAVROS NIARCHOS Foundation-FORTH Fellowship for PhD candidates of the program ARCHERS: Advancing young researchers' human capital in cutting edge technologies in the preservation of cultural heritage and the tackling of societal challenges (ER, EK), and by internal grants from the Biomedical Research Division, IMBB-FORTH (EK) and the University of Ioannina Research Committee (ER, EK). The funders had no role in study design, data collection and analysis, decision to publish, or preparation of the manuscript.

Institutional Review Board Statement: The study was conducted according to the guidelines of the Declaration of Helsinki, and approved by the Institutional Review Board (or Ethics Committee): The scientific and ethics Committee of the University of Ioannina Hospital (8/8-3-2019/@3), and the University Hospital of Heidelberg (\#S315/20; 12 May 2020).

Informed Consent Statement: Any research article describing a study involving humans should contain this statement. Patient consent was waived due to the retrospective nature of the study and the anonymisation of all data.

Data Availability Statement: Not applicable.

Acknowledgments: We are grateful to Michael Kracht, Rudolf Buchheim Institute of Pharmacology, Justus-Liebig University Giessen, Germany, for providing plasmid vectors pSuper-Puro and pSuper-Puro-shp65, and James. E. Goldman, Department of Pathology and Cell Biology, and Irving Comprehensive Cancer Research Center, Medical Center, Columbia University, New York, USA for CD82 retrovectors and antibodies. We thank Georgia Papaspirou and Antigoni Christodoulou, Laboratory of Pathology, University of Ioannina Medical School, Greece, for helping with the immunohistochemistry staining. We also thank Spyridoula Tsiomita for helping with the FACS experiments. We thank Georgios Markopoulos, University of Ioannina, for providing luciferase assay protocols and Periklis Katopodis, Brunel University London, for his help with some of the figures.

Conflicts of Interest: No potential conflict of interest were disclosed.

\section{References}

1. Ding, L.; Getz, G.; Wheeler, D.A.; Mardis, E.R.; McLellan, M.D.; Cibulskis, K.; Sougnez, C.; Greulich, H.; Muzny, D.M.; Morgan, M.B.; et al. Somatic mutations affect key pathways in lung adenocarcinoma. Nature 2008, 455, 1069-1075. [CrossRef]

2. Herbst, R.S.; Heymach, J.V.; Lippman, S.M. Lung cancer. N. Engl. J. Med. 2008, 359, 1367-1380. [CrossRef]

3. Heist, R.S.; Engelman, J.A. SnapShot: Non-small cell lung cancer. Cancer Cell 2012, 21, 448. [CrossRef]

4. Herbst, R.S.; Morgensztern, D.; Boshoff, C. The biology and management of non-small cell lung cancer. Nature 2018, 553, 446-454. [CrossRef]

5. Testa, U.; Castelli, G.; Pelosi, E. Lung Cancers: Molecular Characterization, Clonal Heterogeneity and Evolution, and Cancer Stem Cells. Cancers 2018, 10, 248. [CrossRef] [PubMed]

6. Salehi-Rad, R.; Li, R.; Paul, M.K.; Dubinett, S.M.; Liu, B. The Biology of Lung Cancer: Development of More Effective Methods for Prevention, Diagnosis, and Treatment. Clin. Chest Med. 2020, 41, 25-38. [CrossRef] [PubMed] 
7. Dimitrakopoulos, F.D.; Kottorou, A.E.; Kalofonou, M.; Kalofonos, H.P. The Fire Within: NF-kappaB Involvement in Non-Small Cell Lung Cancer. Cancer Res. 2020, 80, 4025-4036. [CrossRef]

8. LaFave, L.M.; Kartha, V.K.; Ma, S.; Meli, K.; Del Priore, I.; Lareau, C.; Naranjo, S.; Westcott, P.M.K.; Duarte, F.M.; Sankar, V.; et al. Epigenomic State Transitions Characterize Tumor Progression in Mouse Lung Adenocarcinoma. Cancer Cell 2020, $38,212-228$. [CrossRef] [PubMed]

9. Marjanovic, N.D.; Hofree, M.; Chan, J.E.; Canner, D.; Wu, K.; Trakala, M.; Hartmann, G.G.; Smith, O.C.; Kim, J.Y.; Evans, K.V.; et al. Emergence of a High-Plasticity Cell State during Lung Cancer Evolution. Cancer Cell 2020, 38, 229-246. [CrossRef]

10. Farago, A.F.; Snyder, E.L.; Jacks, T. SnapShot: Lung cancer models. Cell 2012, 149, 246. [CrossRef]

11. Meylan, E.; Dooley, A.L.; Feldser, D.M.; Shen, L.; Turk, E.; Ouyang, C.; Jacks, T. Requirement for NF-kappaB signalling in a mouse model of lung adenocarcinoma. Nature 2009, 462, 104-107. [CrossRef]

12. Basseres, D.S.; Ebbs, A.; Levantini, E.; Baldwin, A.S. Requirement of the NF-kappaB subunit p65/RelA for K-Ras-induced lung tumorigenesis. Cancer Res. 2010, 70, 3537-3546. [CrossRef] [PubMed]

13. Xia, Y.; Yeddula, N.; Leblanc, M.; Ke, E.; Zhang, Y.; Oldfield, E.; Shaw, R.J.; Verma, I.M. Reduced cell proliferation by IKK2 depletion in a mouse lung-cancer model. Nat. Cell Biol. 2012, 14, 257-265. [CrossRef]

14. Takahashi, H.; Ogata, H.; Nishigaki, R.; Broide, D.H.; Karin, M. Tobacco smoke promotes lung tumorigenesis by triggering IKKbeta- and JNK1-dependent inflammation. Cancer Cell 2010, 17, 89-97. [CrossRef] [PubMed]

15. Bivona, T.G.; Hieronymus, H.; Parker, J.; Chang, K.; Taron, M.; Rosell, R.; Moonsamy, P.; Dahlman, K.; Miller, V.A.; Costa, C.; et al. FAS and NF-kappaB signalling modulate dependence of lung cancers on mutant EGFR. Nature 2011, 471, 523-526. [CrossRef] [PubMed]

16. Blakely, C.M.; Pazarentzos, E.; Olivas, V.; Asthana, S.; Yan, J.J.; Tan, I.; Hrustanovic, G.; Chan, E.; Lin, L.; Neel, D.S.; et al. NF-kappaB-activating complex engaged in response to EGFR oncogene inhibition drives tumor cell survival and residual disease in lung cancer. Cell Rep. 2015, 11, 98-110. [CrossRef] [PubMed]

17. Pan, D.; Jiang, C.; Ma, Z.; Blonska, M.; You, M.J.; Lin, X. MALT1 is required for EGFR-induced NF-kappaB activation and contributes to EGFR-driven lung cancer progression. Oncogene 2016, 35, 919-928. [CrossRef]

18. Perkins, N.D. Integrating cell-signalling pathways with NF-kappaB and IKK function. Nat. Rev. Mol. Cell Biol. 2007, 8, 49-62. [CrossRef]

19. Perkins, N.D. The diverse and complex roles of NF-kappaB subunits in cancer. Nat. Rev. Cancer 2012, 12, 121-132. [CrossRef]

20. Hayden, M.S.; Ghosh, S. NF-kappaB, the first quarter-century: Remarkable progress and outstanding questions. Genes Dev. 2012, 26, 203-234. [CrossRef]

21. Taniguchi, K.; Karin, M. NF-kappaB, inflammation, immunity and cancer: Coming of age. Nat. Rev. Immunol. 2018, 18, 309-324. [CrossRef] [PubMed]

22. Campbell, K.J.; Rocha, S.; Perkins, N.D. Active repression of antiapoptotic gene expression by RelA(p65) NF-kappa B. Mol. Cell 2004, 13, 853-865. [CrossRef]

23. Penzo, M.; Massa, P.E.; Olivotto, E.; Bianchi, F.; Borzi, R.M.; Hanidu, A.; Li, X.; Li, J.; Marcu, K.B. Sustained NF-kappaB activation produces a short-term cell proliferation block in conjunction with repressing effectors of cell cycle progression controlled by E2F or FoxM1. J. Cell. Physiol. 2009, 218, 215-227. [CrossRef]

24. Giopanou, I.; Lilis, I.; Papaleonidopoulos, V.; Marazioti, A.; Spella, M.; Vreka, M.; Papadaki, H.; Stathopoulos, G.T. Comprehensive Evaluation of Nuclear Factor-kappaBeta Expression Patterns in Non-Small Cell Lung Cancer. PLoS ONE 2015, 10, e0132527. [CrossRef] [PubMed]

25. Stathopoulos, G.T.; Sherrill, T.P.; Cheng, D.S.; Scoggins, R.M.; Han, W.; Polosukhin, V.V.; Connelly, L.; Yull, F.E.; Fingleton, B.; Blackwell, T.S. Epithelial NF-kappaB activation promotes urethane-induced lung carcinogenesis. Proc. Natl. Acad. Sci. USA 2007, 104, 18514-18519. [CrossRef]

26. Chavdoula, E.; Habiel, D.M.; Roupakia, E.; Markopoulos, G.S.; Vasilaki, E.; Kokkalis, A.; Polyzos, A.P.; Boleti, H.; Thanos, D.; Klinakis, A.; et al. CHUK/IKK-alpha loss in lung epithelial cells enhances NSCLC growth associated with HIF up-regulation. Life Sci. Alliance 2019, 2. [CrossRef] [PubMed]

27. Starczynowski, D.T.; Lockwood, W.W.; Delehouzee, S.; Chari, R.; Wegrzyn, J.; Fuller, M.; Tsao, M.S.; Lam, S.; Gazdar, A.F.; Lam, W.L.; et al. TRAF6 is an amplified oncogene bridging the RAS and NF-kappaB pathways in human lung cancer. J. Clin. Investig. 2011, 121, 4095-4105. [CrossRef] [PubMed]

28. Handschick, K.; Beuerlein, K.; Jurida, L.; Bartkuhn, M.; Muller, H.; Soelch, J.; Weber, A.; Dittrich-Breiholz, O.; Schneider, H.; Scharfe, M.; et al. Cyclin-dependent kinase 6 is a chromatin-bound cofactor for NF-kappaB-dependent gene expression. Mol. Cell 2014, 53, 193-208. [CrossRef]

29. Jurida, L.; Soelch, J.; Bartkuhn, M.; Handschick, K.; Muller, H.; Newel, D.; Weber, A.; Dittrich-Breiholz, O.; Schneider, H.; Bhuju, S.; et al. The Activation of IL-1-Induced Enhancers Depends on TAK1 Kinase Activity and NF-kappaB p65. Cell Rep. 2015, 10, 726-739. [CrossRef]

30. de Wit, E.; van Doremalen, N.; Falzarano, D.; Munster, V.J. SARS and MERS: Recent insights into emerging coronaviruses. Nat. Rev. Microbiol. 2016, 14, 523-534. [CrossRef]

31. Hoffmann, M.; Kleine-Weber, H.; Schroeder, S.; Kruger, N.; Herrler, T.; Erichsen, S.; Schiergens, T.S.; Herrler, G.; Wu, N.H.; Nitsche, A.; et al. SARS-CoV-2 Cell Entry Depends on ACE2 and TMPRSS2 and Is Blocked by a Clinically Proven Protease Inhibitor. Cell 2020, 181, 271-280. [CrossRef] 
32. Yan, R.; Zhang, Y.; Li, Y.; Xia, L.; Guo, Y.; Zhou, Q. Structural basis for the recognition of SARS-CoV-2 by full-length human ACE2. Science 2020, 367, 1444-1448. [CrossRef]

33. Hirano, T.; Murakami, M. COVID-19: A New Virus, but a Familiar Receptor and Cytokine Release Syndrome. Immunity 2020, 52, 731-733. [CrossRef] [PubMed]

34. Del Valle, D.M.; Kim-Schulze, S.; Huang, H.H.; Beckmann, N.D.; Nirenberg, S.; Wang, B.; Lavin, Y.; Swartz, T.H.; Madduri, D.; Stock, A.; et al. An inflammatory cytokine signature predicts COVID-19 severity and survival. Nat. Med. 2020, 26, 1636-1643. [CrossRef] [PubMed]

35. Rendeiro, A.F.; Ravichandran, H.; Bram, Y.; Chandar, V.; Kim, J.; Meydan, C.; Park, J.; Foox, J.; Hether, T.; Warren, S.; et al. The spatial landscape of lung pathology during COVID-19 progression. Nature 2021, 593, 564-569. [CrossRef]

36. Melms, J.C.; Biermann, J.; Huang, H.; Wang, Y.; Nair, A.; Tagore, S.; Katsyv, I.; Rendeiro, A.F.; Amin, A.D.; Schapiro, D.; et al. A molecular single-cell lung atlas of lethal COVID-19. Nature 2021, 595, 114-119. [CrossRef] [PubMed]

37. Schwitalla, S.; Fingerle, A.A.; Cammareri, P.; Nebelsiek, T.; Goktuna, S.I.; Ziegler, P.K.; Canli, O.; Heijmans, J.; Huels, D.J.; Moreaux, G.; et al. Intestinal tumorigenesis initiated by dedifferentiation and acquisition of stem-cell-like properties. Cell 2013, 152, 25-38. [CrossRef]

38. Zhan, T.; Rindtorff, N.; Boutros, M. Wnt signaling in cancer. Oncogene 2017, 36, 1461-1473. [CrossRef]

39. Zoller, M. Tetraspanins: Push and pull in suppressing and promoting metastasis. Nat. Rev. Cancer 2009, 9, 40-55. [CrossRef]

40. Tsai, Y.C.; Weissman, A.M. Dissecting the diverse functions of the metastasis suppressor CD82/KAI1. FEBS Lett. 2011, 585, 3166-3173. [CrossRef]

41. Feng, J.; Huang, C.; Wren, J.D.; Wang, D.W.; Yan, J.; Zhang, J.; Sun, Y.; Han, X.; Zhang, X.A. Tetraspanin CD82: A suppressor of solid tumors and a modulator of membrane heterogeneity. Cancer Metastasis Rev. 2015, 34, 619-633. [CrossRef]

42. Drilon, A.; Jenkins, C.; Iyer, S.; Schoenfeld, A.; Keddy, C.; Davare, M.A. ROS1-dependent cancers-biology, diagnostics and therapeutics. Nat. Rev. Clin. Oncol. 2021, 18, 35-55. [CrossRef] [PubMed]

43. Kilvaer, T.K.; Paulsen, E.E.; Andersen, S.; Rakaee, M.; Bremnes, R.M.; Busund, L.R.; Donnem, T. Digitally Quantified CD8+ Cells -The Best Candidate Marker for an Immune Cell Score in NSCLC? Carcinogenesis 2020, 41, 1671-1681. [CrossRef] [PubMed]

44. Zilionis, R.; Engblom, C.; Pfirschke, C.; Savova, V.; Zemmour, D.; Saatcioglu, H.D.; Krishnan, I.; Maroni, G.; Meyerovitz, C.V.; Kerwin, C.M.; et al. Single-Cell Transcriptomics of Human and Mouse Lung Cancers Reveals Conserved Myeloid Populations across Individuals and Species. Immunity 2019, 50, 1317-1334. [CrossRef]

45. Hanahan, D.; Weinberg, R.A. Hallmarks of cancer: The next generation. Cell 2011, 144, 646-674. [CrossRef] [PubMed]

46. Tam, W.L.; Weinberg, R.A. The epigenetics of epithelial-mesenchymal plasticity in cancer. Nat. Med. 2013, 19, 1438-1449. [CrossRef]

47. Mittal, V. Epithelial Mesenchymal Transition in Tumor Metastasis. Annu. Rev. Pathol. 2018, 13, 395-412. [CrossRef]

48. Dongre, A.; Weinberg, R.A. New insights into the mechanisms of epithelial-mesenchymal transition and implications for cancer. Nat. Rev. Mol. Cell Biol. 2019, 20, 69-84. [CrossRef]

49. Sideridou, M.; Zakopoulou, R.; Evangelou, K.; Liontos, M.; Kotsinas, A.; Rampakakis, E.; Gagos, S.; Kahata, K.; Grabusic, K.; Gkouskou, K.; et al. Cdc6 expression represses E-cadherin transcription and activates adjacent replication origins. J. Cell Biol. 2011, 195, 1123-1140. [CrossRef]

50. Markopoulos, G.S.; Roupakia, E.; Marcu, K.B.; Kolettas, E. Epigenetic Regulation of Inflammatory Cytokine-Induced EpithelialTo-Mesenchymal Cell Transition and Cancer Stem Cell Generation. Cells 2019, 8, 1143. [CrossRef]

51. Min, C.; Eddy, S.F.; Sherr, D.H.; Sonenshein, G.E. NF-kappaB and epithelial to mesenchymal transition of cancer. J. Cell Biochem. 2008, 104, 733-744. [CrossRef]

52. Wu, Y.; Deng, J.; Rychahou, P.G.; Qiu, S.; Evers, B.M.; Zhou, B.P. Stabilization of snail by NF-kappaB is required for inflammationinduced cell migration and invasion. Cancer Cell 2009, 15, 416-428. [CrossRef] [PubMed]

53. Storci, G.; Sansone, P.; Mari, S.; D’Uva, G.; Tavolari, S.; Guarnieri, T.; Taffurelli, M.; Ceccarelli, C.; Santini, D.; Chieco, P.; et al. TNFalpha up-regulates SLUG via the NF-kappaB/HIF1alpha axis, which imparts breast cancer cells with a stem cell-like phenotype. J. Cell Physiol. 2010, 225, 682-691. [CrossRef] [PubMed]

54. Li, C.W.; Xia, W.; Huo, L.; Lim, S.O.; Wu, Y.; Hsu, J.L.; Chao, C.H.; Yamaguchi, H.; Yang, N.K.; Ding, Q.; et al. Epithelialmesenchymal transition induced by TNF-alpha requires NF-kappaB-mediated transcriptional upregulation of Twist1. Cancer Res. 2012, 72, 1290-1300. [CrossRef] [PubMed]

55. Kumar, M.; Allison, D.F.; Baranova, N.N.; Wamsley, J.J.; Katz, A.J.; Bekiranov, S.; Jones, D.R.; Mayo, M.W. NF-kappaB regulates mesenchymal transition for the induction of non-small cell lung cancer initiating cells. PLoS ONE 2013, 8, e68597. [CrossRef]

56. Schliekelman, M.J.; Taguchi, A.; Zhu, J.; Dai, X.; Rodriguez, J.; Celiktas, M.; Zhang, Q.; Chin, A.; Wong, C.H.; Wang, H.; et al. Molecular portraits of epithelial, mesenchymal, and hybrid States in lung adenocarcinoma and their relevance to survival. Cancer Res. 2015, 75, 1789-1800. [CrossRef]

57. Jia, D.; Jolly, M.K.; Tripathi, S.C.; Den Hollander, P.; Huang, B.; Lu, M.; Celiktas, M.; Ramirez-Pena, E.; Ben-Jacob, E.; Onuchic, J.N.; et al. Distinguishing mechanisms underlying EMT tristability. Cancer Converg. 2017, 1, 2. [CrossRef] [PubMed]

58. Hemler, M.E. Tetraspanin functions and associated microdomains. Nat. Rev. Mol. Cell Biol. 2005, 6, 801-811. [CrossRef]

59. Termini, C.M.; Cotter, M.L.; Marjon, K.D.; Buranda, T.; Lidke, K.A.; Gillette, J.M. The membrane scaffold CD82 regulates cell adhesion by altering alpha4 integrin stability and molecular density. Mol. Biol. Cell 2014, 25, 1560-1573. [CrossRef] 
60. Marjon, K.D.; Termini, C.M.; Karlen, K.L.; Saito-Reis, C.; Soria, C.E.; Lidke, K.A.; Gillette, J.M. Tetraspanin CD82 regulates bone marrow homing of acute myeloid leukemia by modulating the molecular organization of N-cadherin. Oncogene 2016, 35, 4132-4140. [CrossRef]

61. Ono, M.; Handa, K.; Withers, D.A.; Hakomori, S. Glycosylation effect on membrane domain (GEM) involved in cell adhesion and motility: A preliminary note on functional alpha3, alpha5-CD82 glycosylation complex in ldlD 14 cells. Biochem. Biophys. Res. Commun. 2000, 279, 744-750. [CrossRef] [PubMed]

62. Tonoli, H.; Barrett, J.C. CD82 metastasis suppressor gene: A potential target for new therapeutics? Trends Mol. Med. 2005, 11, 563-570. [CrossRef] [PubMed]

63. Mela, A.; Goldman, J.E. CD82 blocks cMet activation and overcomes hepatocyte growth factor effects on oligodendrocyte precursor differentiation. J. Neurosci. 2013, 33, 7952-7960. [CrossRef] [PubMed]

64. Cooper, J.; Giancotti, F.G. Integrin Signaling in Cancer: Mechanotransduction, Stemness, Epithelial Plasticity, and Therapeutic Resistance. Cancer Cell 2019, 35, 347-367. [CrossRef]

65. Xu, X.; Rock, J.R.; Lu, Y.; Futtner, C.; Schwab, B.; Guinney, J.; Hogan, B.L.; Onaitis, M.W. Evidence for type II cells as cells of origin of K-Ras-induced distal lung adenocarcinoma. Proc. Natl. Acad. Sci. USA 2012, 109, 4910-4915. [CrossRef] [PubMed]

66. Mainardi, S.; Mijimolle, N.; Francoz, S.; Vicente-Duenas, C.; Sanchez-Garcia, I.; Barbacid, M. Identification of cancer initiating cells in K-Ras driven lung adenocarcinoma. Proc. Natl. Acad. Sci. USA 2014, 111, 255-260. [CrossRef]

67. Lum, D.H.; Matsen, C.; Welm, A.L.; Welm, B.E. Overview of human primary tumorgraft models: Comparisons with traditional oncology preclinical models and the clinical relevance and utility of primary tumorgrafts in basic and translational oncology research. Curr. Protoc. Pharmacol. 2012, 59, 14-22. [CrossRef]

68. Gould, S.E.; Junttila, M.R.; de Sauvage, F.J. Translational value of mouse models in oncology drug development. Nat. Med. 2015, 21, 431-439. [CrossRef]

69. Wu, K.; Liao, X.; Gong, Y.; He, J.; Zhou, J.K.; Tan, S.; Pu, W.; Huang, C.; Wei, Y.Q.; Peng, Y. Circular RNA F-circSR derived from SLC34A2-ROS1 fusion gene promotes cell migration in non-small cell lung cancer. Mol. Cancer 2019, 18, 98. [CrossRef]

70. Yasuda, H.; de Figueiredo-Pontes, L.L.; Kobayashi, S.; Costa, D.B. Preclinical rationale for use of the clinically available multitargeted tyrosine kinase inhibitor crizotinib in ROS1-translocated lung cancer. J. Thorac. Oncol. 2012, 7, 1086-1090. [CrossRef]

71. Baek, S.H.; Ohgi, K.A.; Rose, D.W.; Koo, E.H.; Glass, C.K.; Rosenfeld, M.G. Exchange of N-CoR corepressor and Tip60 coactivator complexes links gene expression by NF-kappaB and beta-amyloid precursor protein. Cell 2002, 110, 55-67. [CrossRef]

72. Li, J.; Peet, G.W.; Balzarano, D.; Li, X.; Massa, P.; Barton, R.W.; Marcu, K.B. Novel NEMO/IkappaB kinase and NF-kappa B target genes at the pre-B to immature B cell transition. J. Biol. Chem. 2001, 276, 18579-18590. [CrossRef]

73. Kim, J.H.; Kim, B.; Cai, L.; Choi, H.J.; Ohgi, K.A.; Tran, C.; Chen, C.; Chung, C.H.; Huber, O.; Rose, D.W.; et al. Transcriptional regulation of a metastasis suppressor gene by Tip60 and beta-catenin complexes. Nature 2005, 434, 921-926. [CrossRef] [PubMed]

74. Liu, Y.; Mayo, M.W.; Nagji, A.S.; Smith, P.W.; Ramsey, C.S.; Li, D.; Jones, D.R. Phosphorylation of RelA/p65 promotes DNMT-1 recruitment to chromatin and represses transcription of the tumor metastasis suppressor gene BRMS1. Oncogene 2012, 31, 1143-1154. [CrossRef] [PubMed]

75. Joseph, J.; Mudduluru, G.; Antony, S.; Vashistha, S.; Ajitkumar, P.; Somasundaram, K. Expression profiling of sodium butyrate $(\mathrm{NaB})$-treated cells: Identification of regulation of genes related to cytokine signaling and cancer metastasis by NaB. Oncogene 2004, 23, 6304-6315. [CrossRef] [PubMed]

76. Romanska, H.M.; Berditchevski, F. Tetraspanins in human epithelial malignancies. J. Pathol. 2011, 223, 4-14. [CrossRef] [PubMed]

77. Zhang, X.A.; Lane, W.S.; Charrin, S.; Rubinstein, E.; Liu, L. EWI2/PGRL associates with the metastasis suppressor KAI1/CD82 and inhibits the migration of prostate cancer cells. Cancer Res. 2003, 63, 2665-2674.

78. Zhou, B.; Liu, L.; Reddivari, M.; Zhang, X.A. The palmitoylation of metastasis suppressor KAI1/CD82 is important for its motilityand invasiveness-inhibitory activity. Cancer Res. 2004, 64, 7455-7463. [CrossRef] [PubMed]

79. Zhang, J.; Wu, T.; Zhan, S.; Qiao, N.; Zhang, X.; Zhu, Y.; Yang, N.; Sun, Y.; Zhang, X.A.; Bleich, D.; et al. TIMP-1 and CD82, a promising combined evaluation marker for PDAC. Oncotarget 2017, 8, 6496-6512. [CrossRef]

80. Bassani, S.; Cingolani, L.A. Tetraspanins: Interactions and interplay with integrins. Int. J. Biochem. Cell Biol. 2012, 44, 703-708. [CrossRef]

81. Berditchevski, F.; Odintsova, E. ErbB receptors and tetraspanins: Casting the net wider. Int. J. Biochem. Cell Biol. 2016, 77, 68-71. [CrossRef]

82. Lee, M.S.; Byun, H.J.; Lee, J.; Jeoung, D.I.; Kim, Y.M.; Lee, H. Tetraspanin CD82 represses Sp1-mediated Snail expression and the resultant E-cadherin expression interrupts nuclear signaling of beta-catenin by increasing its membrane localization. Cell. Signal. 2018, 52, 83-94. [CrossRef] [PubMed]

83. Kim, J.H.; Choi, H.J.; Kim, B.; Kim, M.H.; Lee, J.M.; Kim, I.S.; Lee, M.H.; Choi, S.J.; Kim, K.I.; Kim, S.I.; et al. Roles of sumoylation of a reptin chromatin-remodelling complex in cancer metastasis. Nat. Cell Biol. 2006, 8, 631-639. [CrossRef] [PubMed]

84. Dong, J.T.; Lamb, P.W.; Rinker-Schaeffer, C.W.; Vukanovic, J.; Ichikawa, T.; Isaacs, J.T.; Barrett, J.C. KAI1, a metastasis suppressor gene for prostate cancer on human chromosome 11p11.2. Science 1995, 268, 884-886. [CrossRef]

85. Takeda, T.; Hattori, N.; Tokuhara, T.; Nishimura, Y.; Yokoyama, M.; Miyake, M. Adenoviral transduction of MRP-1/CD9 and KAI1/CD82 inhibits lymph node metastasis in orthotopic lung cancer model. Cancer Res. 2007, 67, 1744-1749. [CrossRef] [PubMed] 
86. Bandyopadhyay, S.; Zhan, R.; Chaudhuri, A.; Watabe, M.; Pai, S.K.; Hirota, S.; Hosobe, S.; Tsukada, T.; Miura, K.; Takano, Y.; et al. Interaction of KAI1 on tumor cells with DARC on vascular endothelium leads to metastasis suppression. Nat. Med. 2006, 12, 933-938. [CrossRef] [PubMed]

87. Chairoungdua, A.; Smith, D.L.; Pochard, P.; Hull, M.; Caplan, M.J. Exosome release of beta-catenin: A novel mechanism that antagonizes Wnt signaling. J. Cell Biol. 2010, 190, 1079-1091. [CrossRef]

88. Markopoulos, G.S.; Roupakia, E.; Tokamani, M.; Vartholomatos, G.; Tzavaras, T.; Hatziapostolou, M.; Fackelmayer, F.O.; Sandaltzopoulos, R.; Polytarchou, C.; Kolettas, E. Senescence-associated microRNAs target cell cycle regulatory genes in normal human lung fibroblasts. Exp. Gerontol. 2017, 96, 110-122. [CrossRef]

89. Batsi, C.; Markopoulou, S.; Vartholomatos, G.; Georgiou, I.; Kanavaros, P.; Gorgoulis, V.G.; Marcu, K.B.; Kolettas, E. Chronic NF-kappaB activation delays RasV12-induced premature senescence of human fibroblasts by suppressing the DNA damage checkpoint response. Mech. Ageing Dev. 2009, 130, 409-419. [CrossRef]

90. Sfikas, A.; Batsi, C.; Tselikou, E.; Vartholomatos, G.; Monokrousos, N.; Pappas, P.; Christoforidis, S.; Tzavaras, T.; Kanavaros, P.; Gorgoulis, V.G.; et al. The canonical NF-kappaB pathway differentially protects normal and human tumor cells from ROS-induced DNA damage. Cell. Signal. 2012, 24, 2007-2023. [CrossRef]

91. Lisenko, K.; Leichsenring, J.; Zgorzelski, C.; Longuespee, R.; Casadonte, R.; Harms, A.; Kazdal, D.; Stenzinger, A.; Warth, A.; Kriegsmann, M. Qualitative Comparison Between Carrier-based and Classical Tissue Microarrays. Appl. Immunohistochem. Mol. Morphol. 2017, 25, e74-e79. [CrossRef] [PubMed]

92. Karpathiou, G.; Casteillo, F.; Giroult, J.B.; Forest, F.; Fournel, P.; Monaya, A.; Froudarakis, M.; Dumollard, J.M.; Prades, J.M.; Peoc'h, M. Prognostic impact of immune microenvironment in laryngeal and pharyngeal squamous cell carcinoma: Immune cell subtypes, immuno-suppressive pathways and clinicopathologic characteristics. Oncotarget 2017, 8, 19310-19322. [CrossRef] [PubMed]

93. Camy, F.; Karpathiou, G.; Dumollard, J.M.; Magne, N.; Perrot, J.L.; Vassal, F.; Picot, T.; Mobarki, M.; Forest, F.; Casteillo, F.; et al. Brain metastasis PD-L1 and CD8 expression is dependent on primary tumor type and its PD-L1 and CD8 status. J. Immunother. Cancer 2020, 8. [CrossRef] [PubMed] 